
PREDICTION OF ENZYME CLASSES IN A HIERARCHICAL APPROACH BY USING SPMAP

A THESIS SUBMITTED TO

THE GRADUATE SCHOOL OF NATURAL AND APPLIED SCIENCES

$\mathrm{OF}$

MIDDLE EAST TECHNICAL UNIVERSITY

BY

AYṢE GÜL YAMAN

IN PARTIAL FULFILLMENT OF THE REQUIREMENTS

FOR

THE DEGREE OF MASTER OF SCIENCE

IN

COMPUTER ENGINEERING

SEPTEMBER 2009 
Approval of the thesis:

\section{PREDICTION OF ENZYME CLASSES IN A HIERARCHICAL APPROACH BY USING SPMAP}

submitted by AYṢE GÜL YAMAN in partial fulfillment of the requirements for the degree of Master of Science in Computer Engineering Department, Middle East Technical University by,

Canan Özgen

Dean, Graduate School of Natural and Applied Sciences

Müslüm Bozyig̃it

Head of Department, Computer Engineering

Prof. Dr. Volkan Atalay

Supervisor, Computer Engineering Department, METU

Examining Committee Members:

Assoc. Prof. Dr. Ferda Nur Alpaslan

Computer Engineering Department, METU

Prof. Dr. Volkan Atalay

Computer Engineering Department, METU

Assoc. Prof. Dr. Ali Dog̃ru

Computer Engineering Department, METU

Asst. Prof. Dr. Özlen Konu

Molecular Biology and Genetics Department, Bilkent University

Asst. Prof. Dr. Hasan Og̃ul

Computer Engineering Department, Baskent University

Date: 
I hereby declare that all information in this document has been obtained and presented in accordance with academic rules and ethical conduct. I also declare that, as required by these rules and conduct, $I$ have fully cited and referenced all material and results that are not original to this work.

Name, Last Name: AYṢE GÜL YAMAN

Signature 


\begin{abstract}
PREDICTION OF ENZYME CLASSES IN A HIERARCHICAL APPROACH BY USING SPMAP

Yaman, Ayṣe Gül

M.S., Department of Computer Engineering

Supervisor : Prof. Dr. Volkan Atalay
\end{abstract}

September 2009, 57 pages

Enzymes are proteins that play an important role in biochemical reactions as catalysts. They are classified based on the reaction they catalyzed, in a hierarchical scheme by International Enzyme Commission (EC). This hierarchical scheme is expressed as a four-level tree structure and a unique number is assigned to each enzyme class. There are six major classes at the top level according to the reaction they carried out and sub-classes at the lower levels are further specific reactions of these classes. The aim of this thesis is to build a three-level classification model based on the hierarchical structure of EC classes. ENZYME database is used to extract the information of EC classes and enzymes are assigned to these EC classes. Primary sequences of enzymes extracted from UniProtKB/Swiss-Prot database are used to extract features. A subsequence based feature extraction method, Subsequence Profile Map (SPMap) is used in this study. SPMap is a method that explicitly models the differences between positive and negative examples. SPMap pays attention to the conserved subsequences of protein sequences in the same class. SPMap generates the feature vector of each sample protein as a probability of fixed-length subsequences of this protein with respect to a probabilistic profile matrix calculated by clustering similar subsequences in the training dataset. In our case, positive and negative training datasets are prepared for each class, at each level of 
the tree structure. Subsequence Profile Map (SPMap) is used for feature extraction and Support Vector Machines (SVMs) are used for classification. Five-fold cross validation is used to test the performance of the system. The overall sensitivity, specificity and AUC values for the six major EC classes are $93.08 \%, 98.95 \%$ and 0.993 , respectively. The results at the secondand third- levels are also promising.

Keywords: enzyme classification, SPMap, subsequence-based feature extraction, Enzyme Commission 


\title{
$\ddot{O} \mathbf{z}$
}

\section{SPMAP KULLANARAK ENZIM SINIFLARININ HIYYRARȘIK YAKLAṢIMLA TAHMINI}

\author{
Yaman, Ayșe Gül \\ Yüksek Lisans, Bilgisayar Mühendisligi Bölümü \\ Tez Yöneticisi : Prof. Dr. Volkan Atalay
}

Eylül 2009, 57 sayfa

Enzimler biyokimyasal reaksiyonlarda katalizör olarak önemli rol oynayan proteinlerdir. Enzimler, Uluslararası Enzim Komisyonu tarafından, katalize ettikleri reaksiyona bag̃lı olarak hiyerarșik bir düzende sınıflandırılmıṣlardır. Bu hiyerarșik șema dört seviyeli bir ag̃aç yapısı șeklinde ifade edilir ve her bir enzim sınıfı tek bir sayıya atanır. En üst seviyede, yürüttükleri reaksiyona göre baṣlıca altı sınıf bulunur ve daha aṣag̃ı seviyelerdeki alt sınıflar bu sınıfların daha ileri spesifik reaksiyonlarıdır. Bu tezin amacı, Enzim Komisyonu sınıflarının hiyerarșik yapısını kullanarak üç seviyeli bir sınıflandırma modeli inșa etmektir. Enzim Komisyonu sınıf bilgileri ve bu sınıflara ait enzimler ENZYME veritabanı kullanılarak elde edildi. Öznitelikleri oluṣturmak için UniProtKB/Swiss-Prot veritabanından çıkarılan enzimlerin birincil dizileri kullanıldı. Bu çalıșmada altdizilere dayalı bir öznitelik çıkarma yöntemi olan altdizi profili eṣlemesi kullanıldı. Altdizi profili eṣlemesi, pozitif ve negatif örnekler arasındaki farkları açıkça modelleyen bir yöntemdir. Bu yöntemde, aynı sınıfa ait protein dizilerinin korunmus altdizileri dikkate alınır. Her bir protein dizisinin öznitelik vektörü, ögrenme veri kümesindeki benzer altdiziler gruplandırılarak hesaplanan olasılıklı profil matrisine göre proteinin sabit uzunluklu altdizi olasılıkları ile oluṣturulur. Bu çalı̣̦mada, ag̃aç yapısındaki her bir seviyedeki her bir sınıf için pozitif ve negatif veri kümeleri hazırlandı. Öznitelikleri çıkarmak için alt- 
dizi profili eṣlemesi, sınıflandırma için destek vektör makinaları kullanıldı. Sistemin performansını test etmek için beṣli çapraz geçerleme kullanıldı. Baṣlıca altı Enzim Komisyonu sınıfı ic̣in elde edilen genel duyarlılık, özgüllük ve ROC eg̃risinin altındaki alan deg̃erleri sırayla, $93.08 \%, 98.95 \%$ ve 0.993 ' tür. İkinci ve üçüncü seviyelerdeki sonuçlar da umut vericidir.

Anahtar Kelimeler: enzim sınıflandırması, SPMap, altdizi tabanlı öznitelik çıkarımı, Enzim Komisyonu 
To my family and to the memory of my father 


\section{ACKNOWLEDGMENTS}

First of all, I would like to thank my supervisor Prof. Dr. Volkan Atalay, for encouraging and motivating me througout this work. None of this would have been possible without his help and guidance. I would also like to thank Assoc. Prof. Dr. Rengul Atalay for her valuable comments and suggestions about the problem domain from the biological point of view.

I would like to thank Omer Sinan Sarac for his support about SPMap.

I would like to thank my roommates, Oral Dalay, Zerrin Sokmen and Kerem Hadimli for their friendship.

I would like to thank Ozlem Erdas for sharing her latex knowledge and documents with me.

I would like to thank all the staff at the Computer Engineering Department.

Finally, I would like to thank my family, my mother, my brothers and my sister for their endless love and support. 


\section{TABLE OF CONTENTS}

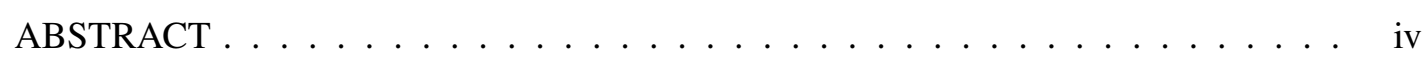

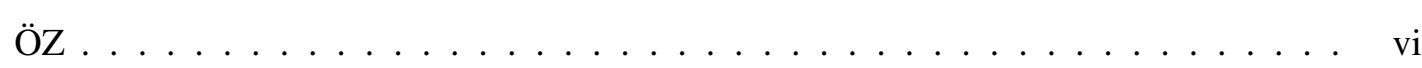

ACKNOWLEDGMENTS .................... ix

TABLE OF CONTENTS ......................

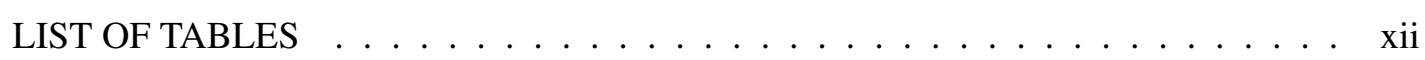

LIST OF FIGURES . . . . . . . . . . . . . . . . . xiv

CHAPTERS

$1 \quad$ INTRODUCTION $\ldots \ldots \ldots \ldots \ldots \ldots$

$1.1 \quad$ Introduction $\ldots \ldots \ldots \ldots \ldots \ldots$

$1.2 \quad$ Problem Statement . . . . . . . . . . . . . 5

$1.3 \quad$ Scope ........................ 6

$1.4 \quad$ Achievements .................... 6

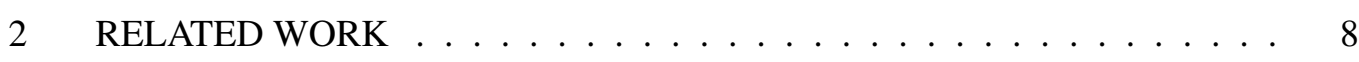

2.1 Enzyme Classification in the Literature . . . . . . . . . . . 8

2.2 Differences of our study from existing methods . . . . . . . . . . . 14

3 DATASETS AND METHODS . . . . . . . . . . . . . . 16

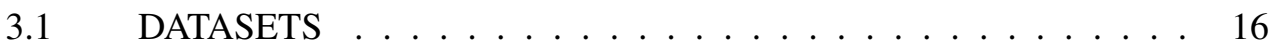

3.1.1 Data Preparation for the First-Level Classification . . . . 18

3.1.2 Data Preparation for the Second-Level Classification . . . 21

3.1.3 Data Preparation for the Third-Level Classification . . . 28

$3.2 \quad$ METHODS . . . . . . . . . . . . . . . . . . . 29

$3.2 .1 \quad$ SPMap $\ldots \ldots \ldots \ldots \ldots \ldots$

3.2.2 Classification .................. 34

3.2.2.1 Linear Support Vector Machines . . . . . . 34 
3.2.2.2 Nonlinear Support Vector Machines _. . . . 39

$4 \quad$ RESULTS AND DISCUSSION $\ldots \ldots \ldots \ldots$

$4.1 \quad$ First-Level EC Classification Results . . . . . . . . . . . . . . . . 41

$4.2 \quad$ Second-Level EC Classification Results . . . . . . . . . . . . . . . 43

$4.3 \quad$ Third-Level EC Classification Results _. . . . . . . . . . . . 47

4.4 Discussion ...................... 53

5 CONCLUSION AND FUTURE WORK . . . . . . . . . . . . . . 54

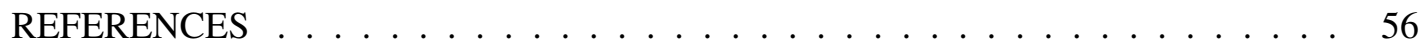




\section{LIST OF TABLES}

\section{TABLES}

Table 1.1 List of 20 amino acids. . . . . . . . . . . . . . . . .

Table 2.1 Review of Studies Involving Prediction of Enzyme Classes. (The abbreviations are, GO : Gene Ontology, PseAA : Pseudo Amino Acid composition, FunD : Functional Domain, Am-Pse-AA : Amphiphilic Pseudo Amino Acid composition, Pse-PSSM : Pseudo Position-Specific Scoring Matrix, CDA : Covariant Discriminant Algorithm, NN : Nearest Neighbor, OET-KNN : Optimized EvidenceTheoretic k Nearest Neighbor, SVMs : Support Vector Machines). . . . . . . . . 14

Table 3.1 An example ENZYME database entry. . . . . . . . . . . . . . . . . . . . 17

Table 3.2 First-level EC classes and their related information. . . . . . . . . . . . . . 17

Table 3.3 Second-Level EC sub-classes and number of proteins. . . . . . . . . . . . . 21

Table 3.4 Kernel functions used for nonlinear SVMs. . . . . . . . . . . . . . . . . . 40

Table 4.1 Confusion Matrix $\ldots \ldots \ldots \ldots \ldots$. . . . . . . . . . . . . 41

Table 4.2 Average Five-fold Cross Validation Results for the First-Level EC Classes , TP : True Positives, FP : False Positives, TN : True Negatives, FN : False Negatives, sens. : sensitivity, spec. : specificity, AUC : Area under the ROC curve. 42

Table 4.3 Average Five-fold Cross Validation Results for the Second-Level EC Classes , TP : True Positives, FP : False Positives, TN : True Negatives, FN : False Negatives, sens. : sensitivity, spec. : specificity, AUC : Area under the ROC curve. 43

Table 4.4 Five-fold Cross Validation Results for EC 1.12, TP : True Positives, FN :

False Negatives, TN : True Negatives, FP : False Positives, sens. : sensitivity, spec. : specificity , AUC : Area under the ROC curve. . . . . . . . . . . . . . 46 
Table 4.5 Five-fold Cross Validation Results for EC 3.8, TP : True Positives, FN : False Negatives, TN : True Negatives, FP : False Positives, sens. : sensitivity, spec. : specificity , AUC : Area under the ROC curve. . . . . . . . . . . . . . . 46

Table 4.6 Average Five-fold Cross Validation Results for the Third-Level EC Classes , TP : True Positives, FP : False Positives, TN : True Negatives, FN : False Negatives, sens. : sensitivity, spec. : specificity, AUC : Area under the ROC curve. 47 


\section{LIST OF FIGURES}

\section{FIGURES}

Figure 1.1 Levels of protein structures (Adopted from [33]) . . . . . . . . . . . . . . 3

Figure 1.2 Hierarchical tree structure of Enzyme Commission Classes. . . . . . . . . 4

Figure 2.1 A flowchart to show (A) how to use the FunD approach and Pse-PSSP approach into a prediction engine, and (B) how the top-down approach of the 3layer predictor works (Adopted from [40]) . . . . . . . . . . . . . . . . . 11

Figure 3.1 Graphical representation of the tree structure showing the positive and negative EC sub-sub-subclasses selected to prepare training datasets for EC 1 - Oxidoreductases (The nodes with blue, solid lines represent the positive classes and the nodes with red, dashed lines represent the negative classes) . . . . . . . . . . . 19

Figure 3.2 Graphical representation of the tree structure showing the positive and negative EC sub-sub-subclasses selected to prepare training datasets for EC 1.1 - Oxidoreductases acting on the $\mathrm{CH}-\mathrm{OH}$ group (The nodes with blue, solid lines represent the positive classes and the nodes with red, dashed lines represent the negative classes).

Figure 3.3 Graphical representation of the tree structure showing the positive and negative EC sub-sub-subclasses selected to prepare training datasets for EC 1.1.1 Oxidoreductases acting on the $\mathrm{CH}-\mathrm{OH}$ group with NAD or NADP as acceptor (The nodes with blue, solid lines represent the positive classes and the nodes with red, dashed lines represent the negative classes). . . . . . . . . . . . . . . . 28

Figure 3.4 Steps and general flow of SPMap. 1) Subsequence extraction. 2) Clustering. 3) Probabilistic profile matrix construction. 4) Feature vector generation. . . . 30

Figure 3.5 Flowchart of the clustering algorithm. . . . . . . . . . . . 31

Figure 3.6 Blosum62 amino acid similarity matrix $[25] \ldots \ldots \ldots$. . . . . . . . . 32 
Figure 3.7 Linear separating hyperplanes for separable SVM. (Adopted from [10]) . . 35

Figure 3.8 Linear separating hyperplanes for non-separable SVM. (Adopted from [10]) 37 


\section{CHAPTER 1}

\section{INTRODUCTION}

\subsection{Introduction}

Enzymes are proteins that catalyse biochemical reactions by which matter and energy are transformed inside living cells [34]. They lower the activation energy and speed up the rate of the biochemical reactions. Specific reactant molecules called substrates bind to a particular site on the enzyme surface called the active site, where catalytic activities take place. Enzymes bind a substrate to the active site and produce an enzyme-substrate complex, then enzymesubstrate complex breaks to the product and enzyme.

Enzyme + Substrate $\Rightarrow$ Enzyme-Substrate Complex $\Rightarrow$ Product + Enzyme

Enzymes don't alter after the reactions and they can then take place in other biochemical reactions.

Enzymes are proteins and proteins are polypeptide chains that are made up of amino acids. There are 20 types of amino acids that naturally occur in the nature (Table 1.1). Amino acids are the basic building blocks of polypeptide chains. There are four levels of protein structures (Figure 1.1). The primary structure of a protein is the chain of amino acids that are linked by peptide bonds. By the development of DNA sequencing methods, three consecutive DNA base sequences are translated to obtain the amino acid sequence of a protein. The amino acid sequence has the information of structural and biological properties and functions of a protein. Secondary structures include $\alpha$ helices, $\beta$ sheets, loops, turns and other forms that are formed by the interactions between amino acids in the polypeptide. Tertiary structure is the three-dimensional structure of a protein formed by folding of secondary structures of a polypeptide chain. Quaternary structure is the structures of several polypeptide chains inter- 
acting with each other. The primary structure of a protein determines the protein's tertiary structure. Polypeptide chains fold into three-dimensional structures and it is this structure that determines the function of an enzyme (i.e. protein).

Table 1.1: List of 20 amino acids.

\begin{tabular}{|c|c|c|}
\hline $\begin{array}{c}\text { one-letter } \\
\text { abbreviation }\end{array}$ & $\begin{array}{c}\text { three-letter } \\
\text { abbreviation }\end{array}$ & full name \\
\hline $\mathrm{A}$ & Ala & Alanine \\
\hline $\mathrm{R}$ & Arg & Arginine \\
\hline $\mathrm{N}$ & Asn & Asparagine \\
\hline $\mathrm{D}$ & Asp & Aspartic acid \\
\hline $\mathrm{C}$ & Cys & Cysteine \\
\hline Q & Gln & Glutamine \\
\hline E & Glu & Glutamic acid \\
\hline G & Gly & Glycine \\
\hline $\mathrm{H}$ & His & Histidine \\
\hline I & Ile & Isoleucine \\
\hline $\mathrm{L}$ & Leu & Leucine \\
\hline K & Lys & Lysine \\
\hline M & Met & Methionine \\
\hline $\mathrm{F}$ & Phe & Phenylalanine \\
\hline$P$ & Pro & Proline \\
\hline$S$ & Ser & Serine \\
\hline $\mathrm{T}$ & Thr & Threonine \\
\hline $\mathrm{W}$ & $\operatorname{Trp}$ & Tryptophan \\
\hline $\mathrm{Y}$ & Tyr & Tyrosine \\
\hline V & Val & Valine \\
\hline
\end{tabular}


From Protein Structure and Function

by Gregory A Petsko and Dagmar Ringe

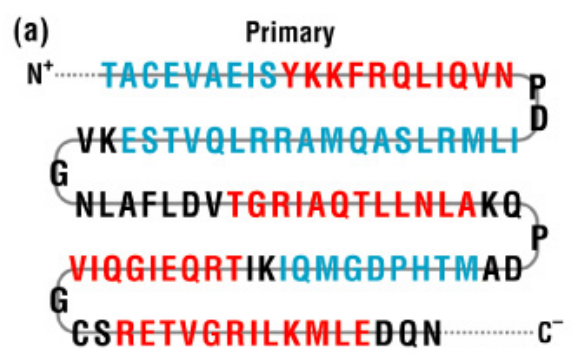

(b)

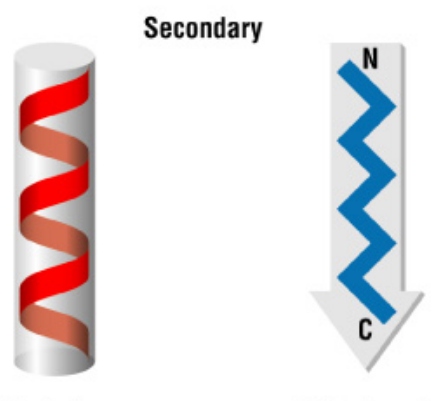

alpha helices

beta strands

(c)

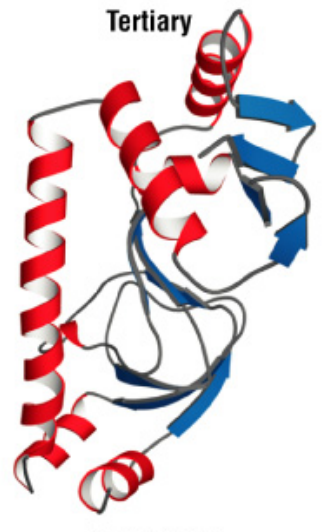

(d)

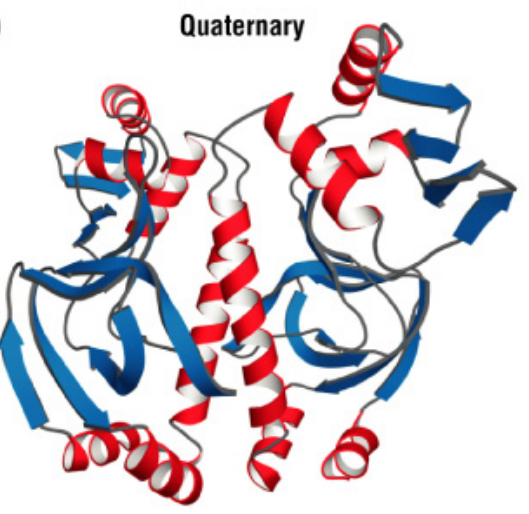

두 1999-2004 New Science Press

Figure 1.1: Levels of protein structures (Adopted from [33]). 
Enzymes are classified by International Union of Biochemistry and Molecular Biology (IUBMB) according to the reaction they catalyze. IUBMB developed a hierarchical tree structure (Figure 1.2) with four-levels and a numbering system is used, containing four digits representing each of four levels separated by periods. The type of the reaction is used to assign Enzyme Commission (EC) numbers to enzymes. For an EC number, EC 11.12.13.14; 11 represents one of the six main classes of biochemical reactions, 12 is the subclass by the type of substrate or the bond cleaved, 13 is the sub-subclass by the electron acceptor or the type of group removed and 14 is the sub-sub-subclass that is the serial number of enzyme.

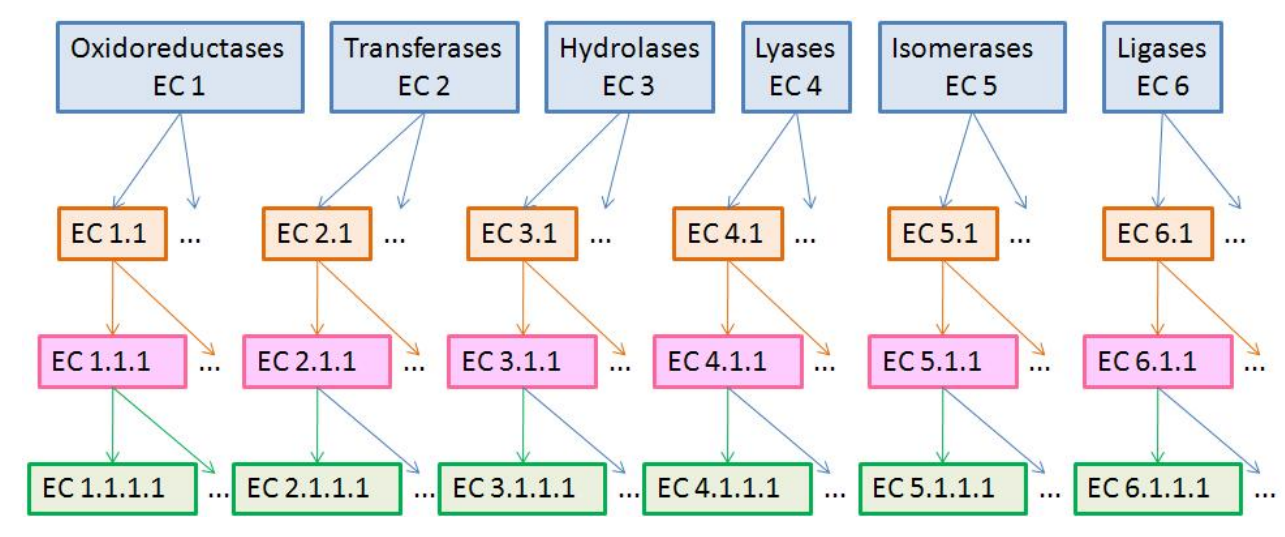

Figure 1.2: Hierarchical tree structure of Enzyme Commission Classes.

The six major Enzyme Commission classes are as follows.

- Oxidoreductases (EC 1) : enzymes catalyzing oxidation reduction reactions.

- Transferases (EC 2) : enzymes catalyzing transfer of functional groups.

- Hydrolases (EC 3) : enzymes catalyzing hydrolysis reactions.

- Lyases (EC 4) : enzymes catalyzing group elimination reactions to form double bonds.

- Isomerases (EC 5) : enzymes catalyzing isomerizations.

- Ligases (EC 6) : enzymes catalyzing bond formation reactions couples with ATP hydrolysis. 


\subsection{Problem Statement}

The number of known enzymes increase rapidly. In vivo experiments to decide the function of the newly discovered enzymes are time-consuming and costly. For this reason, computational methods can be used to assign the known enzyme functions to novel enzymes. Computational methods use the structure of the known enzymes, train the classifiers using the features generated from the known enzymes and use the trained classifiers to determine the functions of novel enzymes. Although the function of an enzyme is determined by the tertiary structure, the tertiary structure of most of the enzymes is not known. On the other hand, the primary structure that is the sequence information of most of the enzymes in the ENZYME database can easily be obtained from UniprotKB/Swiss-Prot sequence database. In this study, the primary sequences of enzymes are used to generate features for classification.

Discriminative methods, such as Support Vector Machines (SVMs) construct decision boundaries between positive and negative training samples, therefore selection of positive and negative samples is an important task for these methods to make an accurate distinction between these two set of samples. In our case, for an EC class, $C$, enzymes belonging to the class $C$ can be used to prepare the positive dataset, but use of all remaining enzymes for negative training dataset would cause an imbalance problem between the datasets. Therefore, representative enzymes should be selected from the remaining EC classes to prepare the negative training dataset.

Another issue for the classification of enzymes is the choice of feature extraction method. In the literature there are a few methods used for functional classification of enzymes using primary sequence information [31]. These are homology-, feature- and subsequence-based approaches. Homology-based approaches use sequence similarity algorithms such as FASTA and BLAST to find homolog proteins of the query protein from a sequence database and annotates the same function to the query protein. This approach cannot be used with discriminative methods since only positive samples are taken into account in the sequence database. Featurebased approaches extract biologically meaningful properties from the primary sequences to represent the proteins. Feature-based approaches use classification algorithms to assign the functions to the proteins. Subsequence-based approaches use conserved subsequences called motifs or domains to represent the protein sequences. Motifs and domains are subsequences among a class of proteins which are known to have important informations about the func- 
tions of the proteins. Subsequence-based approaches in the literature use motifs or domains from existing databases which causes computational complexity problems because of the high dimensional and sparse feature vectors.

\subsection{Scope}

Our aim in this study is to classify enzymes in a top-down manner, using the hierarchical tree structure defined by IUBMB, starting from the first-level and continue with the lower levels. However, the number of enzymes assigned to the classes at the lower levels are not enough to prepare training datasets for classification. Therefore, training is done only with the classes having more than 25 enzymes. It is possible to do classification for the first-, second- and third-level classes with the currently existing number of enzymes at the ENZYME database. There are some classes with less than 25 enzymes at the third-level but this number can still be tolerated. At the fourth-level, the number of enzymes are not enough to perform statistically significant classification.

\subsection{Achievements}

Enzyme classification studies in the literature perform classification for the first- and secondlevels, yet we haven't seen an application of the third-level classification. We performed binary classification for the first-, second- and third-levels of EC hierarchy. The results are promising for all levels. At the first-level, we trained 30 binary classifiers for all $6 \mathrm{EC}$ classes. At the second-level, 285 binary classifiers are trained for 57 sub-classes among 60, which is more than the number of sub-classes employed by previous studies. At the third-level, 700 binary classifiers are trained for 140 sub-subclasses among 207 sub-subclasses which is promising since third-level classification hasn't been investigated before. Totally 1015 binary classifiers are trained for 203 classes in this thesis.

Preparation of positive and negative datasets is an important issue for discriminative models. In our study, we develop an algorithm to prepare representative samples for positive and negative datasets, for each fold of the 5-fold cross-validation, for the EC classes at each level. It is observed that consistent results are produced compared to the classification results of using datasets with randomly selected enzymes. We also use only enzymes to prepare positive 
and negative datasets while most of the existing studies use non-enzyme proteins for negative datasets.

In this study, we use a subsequence-based approach called Subsequence Profile Map (SPMap) [35] to extract features for classification which uses information of all fixed-length subsequences of proteins in the training dataset to extract features. In most of the previous approaches, explained in detail in the next chapter, proteins with high sequence identity are not used for training. In our approach, we don't remove these proteins from the training datasets, because SPMap takes into account all the subsequences of the protein sequences in the training dataset and we don't want to disregard any subsequences that may indicate the function of the protein.

The classification system developed in this study can be used by biologists for functional annotation of microbial proteomes most of which are enzymes. The improvements in the sequencing technologies give rise to increment in the number of sequenced microbial genomes $[8,24]$. Computational methods are useful to predict the functions of microbial proteomes encoded by these genomes. Automated methods used for genome annotation are reviewed in $[41,30]$. Our classification system would be useful for predicting functions of enzymes encoded by newly sequenced microbial organism genomes. 


\section{CHAPTER 2}

\section{RELATED WORK}

\subsection{Enzyme Classification in the Literature}

In the literature, there are a few studies about the prediction or classification of Enzyme Commission (EC) classes using primary sequence information. We analyzed these studies according to the following criteria :

- employed datasets,

- feature extraction methods (homology-, feature- or subsequence-based approaches),

- classification or prediction systems developed to predict or classify the class of the novel enzyme sequences using the extracted features.

In general, the ENZYME [5] or BRENDA [37] databases were used to extract the information of Enzyme Commission (EC) classes and UniProtKB/Swiss-Prot [44] database was used to extract enzyme sequences.

Chou and Elrod [17] proposed a feature-based prediction system for the second-level subclasses of oxidoreductases (EC 1), selected from the ENZYME database. The prediction was performed by 16 sub-classes of oxidoreductases, each of which had more than 50 enzymes. The enzyme sequences labeled with these EC sub-classes were extracted from UniProtKB/SwissProt database. Enzymes assigned to multiple classes were removed from the dataset. The feature vectors were generated by using the amino acid composition of the enzyme sequences. The covariant discriminant function algorithm [15] was used to predict the EC class of a query enzyme. The performance was assessed by re-substitution test and jackknife test. The overall 
success rate was $75.45 \%$ in the re-substitution test and $63.64 \%$ in the jackknife test.

The prediction system proposed by Cai et al. [14] used both subsequence- and feature-based approaches. Initially, they performed a prediction between enzymes and non-enzymes and further prediction was made with the six major EC classes. The dataset included 12520 enzyme sequences labeled by the six main EC classes (2314 oxidoreductases, 3653 transferases, 3246 hydrolases, 1307 lyases, 676 isomerases, 1324 ligases) extracted from ENZYME database and 27469 non-enzyme sequences extracted randomly from UniProtKB/SwissProt database. All sequences had less than $60 \%$ sequence identity. The enzymes were represented by hybridizing gene product composition and amino acid composition. Gene product composition is a subsequence-based approach, using 1930 dimensional GO_compress database developed by Chou and Cai [18] containing mappings of InterPro functional domain database [2] entries to Gene Ontology (GO) [3]. The enzyme sequences were represented by 1930-dimensional feature vectors, if there was a hit in the InterPro functional domain database. Otherwise, the feature-based approach, amino acid composition [16, 19], was used to represent the enzymes by 57-dimensional vectors. After the generation of feature vectors, Nearest Neighbor $(\mathrm{NN})$ prediction was used to predict the class of a query enzyme. The performance of the system was assessed by re-substitution test, jackknife test and independent test. According to the jackknife test, the success rate for enzymes was $95.61 \%$, non-enzymes was $93.49 \%$ and overall success rate was $94.15 \%$. Among the six main enzyme classes, the success rate for oxidoreductases (EC 1), transferases (EC 2), hydrolases (EC 3), lyases (EC 4), isomerases (EC 4), ligases (EC 5) were 98.98\%, 99.13\%, 98.87\%, 97.18\%, 96.77\%, 96.75\%, respectively and the overall success rate was $98.48 \%$.

Cai and Chou [13] later introduced a subsequence-based approach to make a prediction between enzymes and non-enzymes, and six major Enzyme Commission (EC) classes. 1000 enzymes, having less than 20\% sequence identity were extracted from the ENZYME database and 1301 non-enzyme protein sequences with less than $20 \%$ sequence identity were extracted from UniProtKB/Swiss-Prot database. 7785 functional domains extracted from the InterPro functional domain database were used to represent the proteins as 7785-dimensional feature vectors. The EC classes of a novel protein was predicted by Nearest Neighbor (NN) method. The overall success rate was $85.35 \%$. 
Chou [19] introduced the amphiphilic pseudo amino acid composition (Am-Pse-AA) to represent enzyme sequences. Am-Pse-AA had information about the order of protein sequence and distribution of the hydrophobic and hydrophilic amino acids along the chain. The same dataset (16 sub-classes of oxidoreductases) constructed by Chou and Elrod [17] was used to compare the performance of the method with the previous one. The enzyme classes were predicted by the covariant discriminant algorithm. The overall success rate of the re-substitution test was $92.16 \%$ and the jackknife test was $70.61 \%$.

EzyPred is a 3-layer online prediction tool developed by Shen and Chou [40] that makes a prediction between enzymes and non-enzymes at the 1st layer, six major enzyme classes at the 2nd layer and sub-classes of the major enzyme classes at the 3 rd layer. To prepare the datasets, they extracted 9850 non-enzyme protein sequences randomly from the UniProtKB/SwissProt database. The enzymes for enzyme classes were extracted from ENZYME database and enzyme sequences with less than 50 amino acids, having multiple enzyme classes or having more than $40 \%$ sequence identity were removed. 9832 enzymes labeled with six main enzyme classes were obtained. The sub-classes having more than 10 enzyme sequences were used for statistical significance. Two feature vectors were generated for protein sequences, using the Functional Domain (FunD) approach and Pseudo Position-Specific Scoring Matrix (PsePSSM) approach. In the FunD approach, 8958 functional domains were extracted from Pfam database [6]. A protein sequence was represented by an 8958-dimensional feature vector, each entry taking the value 1 if the corresponding domain exists in the protein sequence, otherwise 0 . Another representation of the protein sequence was by pseudo position-specific scoring matrix (Pse-PSMM) adopted from [16] and [19]. A modified version of $k$ Nearest Neighbor classifier, called optimized evidence-theoretic $k$ nearest neighbor (OET-KNN) classifier [21, $38,45]$ was used for the prediction of a novel protein sequence. The OET-KNN classifier was trained by the FunD feature vector and Pse-PSSM feature vector, a voting score was calculated by fusing the results and the class of the query protein was predicted as the one with the highest score. Figure 2.1 illustrates the fusion approach and the 3-layer prediction approach. The success rate obtained by the jackknife test was $92.4 \%$ for enzymes and $90.1 \%$ for non-enzymes. The success rate of oxidoreductases (EC 1), transferases (EC 2), hydrolases (EC 3), lyases (EC 4), isomerases (EC 5) and ligases (EC 6) were 91.4\%, 94.5\%, 97.1\%, $85.1 \%, 83.6 \%$ and $96.5 \%$, respectively. The overall success rate was $93.7 \%$. The overall success rates of sub-classes of oxidoreductases, transferases, hydrolases, lyases, isomerases 
A

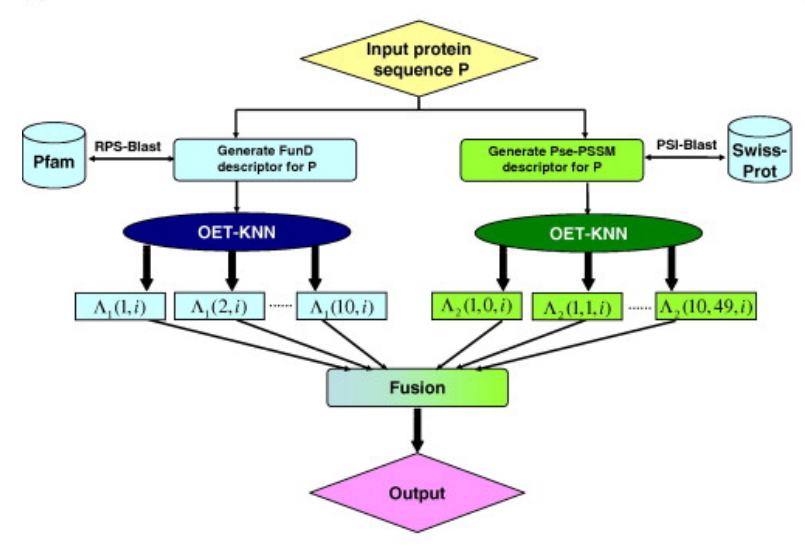

B

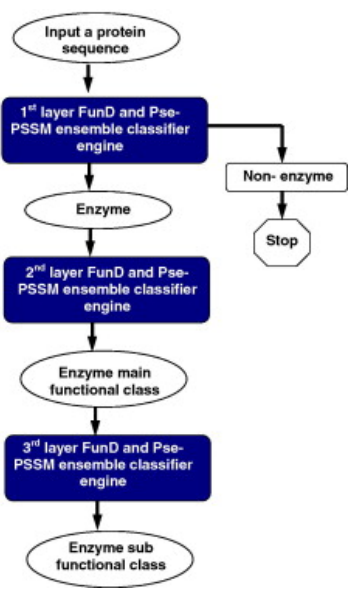

Figure 2.1: A flowchart to show (A) how to use the FunD approach and Pse-PSSP approach into a prediction engine, and (B) how the top-down approach of the 3-layer predictor works (Adopted from [40])

Cai et al. [11, 12] developed a web-based discriminative classification system, SVM-Prot, for the functional classification of proteins from primary sequences. They prepared positive and negative datasets for different functional families of enzymes beyond Enzyme Commission classes. Enzyme families (i.e. Enzyme Commission classes) included 46 second-level subclasses extracted from BRENDA database [37]. The positive training dataset contained the proteins assigned to an enzyme family and the negative training samples for this family were extracted from protein families in the Pfam database [6] including both enzymes from other enzyme families and non-enzyme proteins. The protein features were represented by the combination of composition, transition and distribution descriptors that described the composition of physicochemical properties of residues in the protein sequences such as amino acid composition, hydrophobicity, normalized Van der Waals volume, polarity, polarizability, charge, surface tension, secondary structure and solvent accessibility. The classifier was trained with positive and negative datasets by Support Vector Machines (SVMs) to classify novel protein sequences. The sensitivity, specificity and Matthews correlation coefficient values for the 46 Enzyme Commission (EC) sub-classes were in the range of 50\% to $95.7 \%, 79.0 \%$ to $96.1 \%$, and $54.1 \%$ to $96.1 \%$, respectively.

Lu et al. [29] developed an online Enzyme Classification System (ECS) to identify enzymes and non-enzymes as well as six enzyme classes using a subsequence-based approach based on 
the functional domain composition of proteins. ENZYME database was used to prepare the positive dataset (enzymes) and UniProtKB/Swiss-Prot database was used to prepare the negative dataset (non-enzymes). 70573 enzymes were extracted for six major enzyme classes and 145271 proteins were extracted for non-enzymes. 2657 functional domains were extracted form Pfam database for enzymes and non-enzymes and each protein was represented with a 2657-dimensional feature vector. Support Vector Machines (SVMs) were used for classification. According to jackknife test the success rate of enzymes was $76.30 \%$, non-enzymes was $90.89 \%$ and success rate of the overall prediction was $86.03 \%$. Success rate for oxidoreductases (EC 1), transferases (EC 2), hydrolases (EC 3), lyases (EC 4), isomerases (EC 5) and ligases (EC 6) were 93.35\%, 93.63\%, 94.20\%, 75.29\%, 74.56\% and 89.33\%, respectively. The overall success rate of six main enzyme classes was $91.32 \%$.

One of the earliest studies about prediction of enzyme classes was a homology based approach presented by Shah and Hunter [39]. Sequence similarity methods were applied to predict Enzyme Commission (EC) classes. The number of enzymes assigned to the EC classes and the number of subclasses were very fewer compared to the numbers we used in this thesis. The number of enzymes labeled with oxidoreductases, transferases, hydrolases, lyases, isomerases and ligases were 3766, 4363, 4649, 1604, 576 and 655, respectively, whereas in our study these numbers are increased to $28539,49425,29890,14264,8225$ and 18336, respectively. They applied the sequence database similarity search algorithms FASTA [32] and BLAST [1] to predict the EC classes of 13215 enzyme sequences extracted from UniProtKB/Swiss-Prot labeled with EC numbers. Because of the under sampling problem they couldn't cover all enzyme classes. The performance of the system was assessed by FASTA z-score and BLAST expectation measures. There wasn't a significant difference between the performances of FASTA and BLAST. Over 13215 proteins, the EC classes of 12150 proteins were correctly predicted.

Table 2.1 summarizes the key aspects of previous studies according to the datasets, feature extraction methods and prediction or classification methods. 
Table 2.1: Review of Studies Involving Prediction of Enzyme Classes. (The abbreviations are, GO : Gene Ontology, PseAA : Pseudo Amino Acid composition, FunD : Functional Domain, Am-Pse-AA : Amphiphilic Pseudo Amino Acid composition, Pse-PSSM : Pseudo Position-Specific Scoring Matrix, CDA : Covariant Discriminant Algorithm, NN : Nearest Neighbor, OET-KNN : Optimized Evidence-Theoretic k Nearest Neighbor, SVMs : Support Vector Machines).

\begin{tabular}{|l|l|l|c|}
\hline Name & Dataset & Feature Extraction & $\begin{array}{c}\text { Prediction } \\
\text { or } \\
\text { Classification }\end{array}$ \\
\hline Chou and Elrod (2003) [17] & 16 sub-classes of EC 1 & amino acid composition & CDA \\
\hline Cai et al. (2004) [14] & $\begin{array}{l}\text { non-enzymes } \\
6 \text { major EC classes }\end{array}$ & GO-PseAA & NN \\
\hline Cai and Chou (2005) [13] & $\begin{array}{l}\text { non-enzymes } \\
6 \text { main EC classes }\end{array}$ & $\begin{array}{l}\text { FunD } \\
\text { InterPro database }\end{array}$ & NN \\
\hline Chou (2005) [19] & $\begin{array}{l}\text { 16 sub-classes of EC 1 } \\
\text { Am-Pse-AA }\end{array}$ & CDA \\
\hline Shen and Chou (2007) [40] & $\begin{array}{l}\text { non-enzymes } \\
\text { second-level sub-classes }\end{array}$ & $\begin{array}{l}\text { FunD } \\
\text { Pse-PSSM }\end{array}$ & OET-KNN \\
\hline Lu et al. (2007) [29] & $\begin{array}{l}\text { non-enzymes } \\
\text { major EC classes }\end{array}$ & $\begin{array}{l}\text { FunD } \\
\text { Pfam }\end{array}$ & SVMs \\
\hline Shah and Hunter (1997) [39] & all EC classes & sequence similarity & FASTA and BLAST \\
\hline
\end{tabular}

\subsection{Differences of our study from existing methods}

- We train binary classifiers for the third-level EC sub-subclasses beyond the first-level EC classes and second-level EC subclasses.

- Subsequence-based approaches in the literature use subsequences already available at the motif or domain databases. In our study, subsequences extracted from the training dataset are used to generate the feature vectors.

- An algorithm is developed to prepare positive and negative training datasets for the binary classifiers, in order to extract representative enzymes from all sub-sub-subclasses on the hierarchical tree structure to improve the predictive performance of the classification system. 
- Most of the existing approaches remove the proteins with high sequence identity from the training datasets. We didn't make such a restriction while preparing the training datasets not to loose the subsequences that might be important while extracting features by SPMap.

- Preparation of negative datasets is not explained clearly, in the previous studies. 


\section{CHAPTER 3}

\section{DATASETS AND METHODS}

\subsection{DATASETS}

In this study, a three-level binary classification system is developed using the hierarchical tree structure of the Enzyme Commission (EC) classes defined by Enzyme Nomenclature Committee of International Union of Biochemistry and Molecular Biology (IUBMB) [23]. There are four levels in the tree structure of the hierarchical scheme. Positive and negative datasets are prepared for 6 classes at the first-level, 57 sub-classes at the second-level and 140 sub-subclasses at the third-level. The sub-sub-subclasses at the fourth-level don't have enough number of samples, therefore they are not considered. Subsequence Profile Map (SPMAP) [35] is used for feature extraction and Support Vector Machines (SVM) [22] are used for classification. Five-fold cross-validation is used to test the performance of the system.

EC numbers and Uniprot/Swiss-Prot accession numbers of enzymes are extracted from the ENZYME database (release of 20-Jan-2009) [5]. Table 3.1 shows a sample ENZYME database entry. Only, ID and DR lines are used to extract information for the preparation of datasets. The ID (IDentification) line gives the EC number. The EC numbers at the ENZYME database are identified as EC a.b.c.d. Here ' $a$ ' is the number of the class at the first-level, ' $b$ ' is the number of the sub-class at the second-level, 'c' is the number of the sub-subclass at the third-level and ' $\mathrm{d}$ ' is the number of the sub-sub-subclass at the fourth-level. The DR (Database Reference) lines contain the UniProtKB/Swiss-Prot accession numbers of enzymes assigned to the EC numbers. The primary sequences of enzymes are extracted from UniProtKB/Swiss-Prot (release 14.7 20-Jan2009). 
Table 3.1: An example ENZYME database entry.

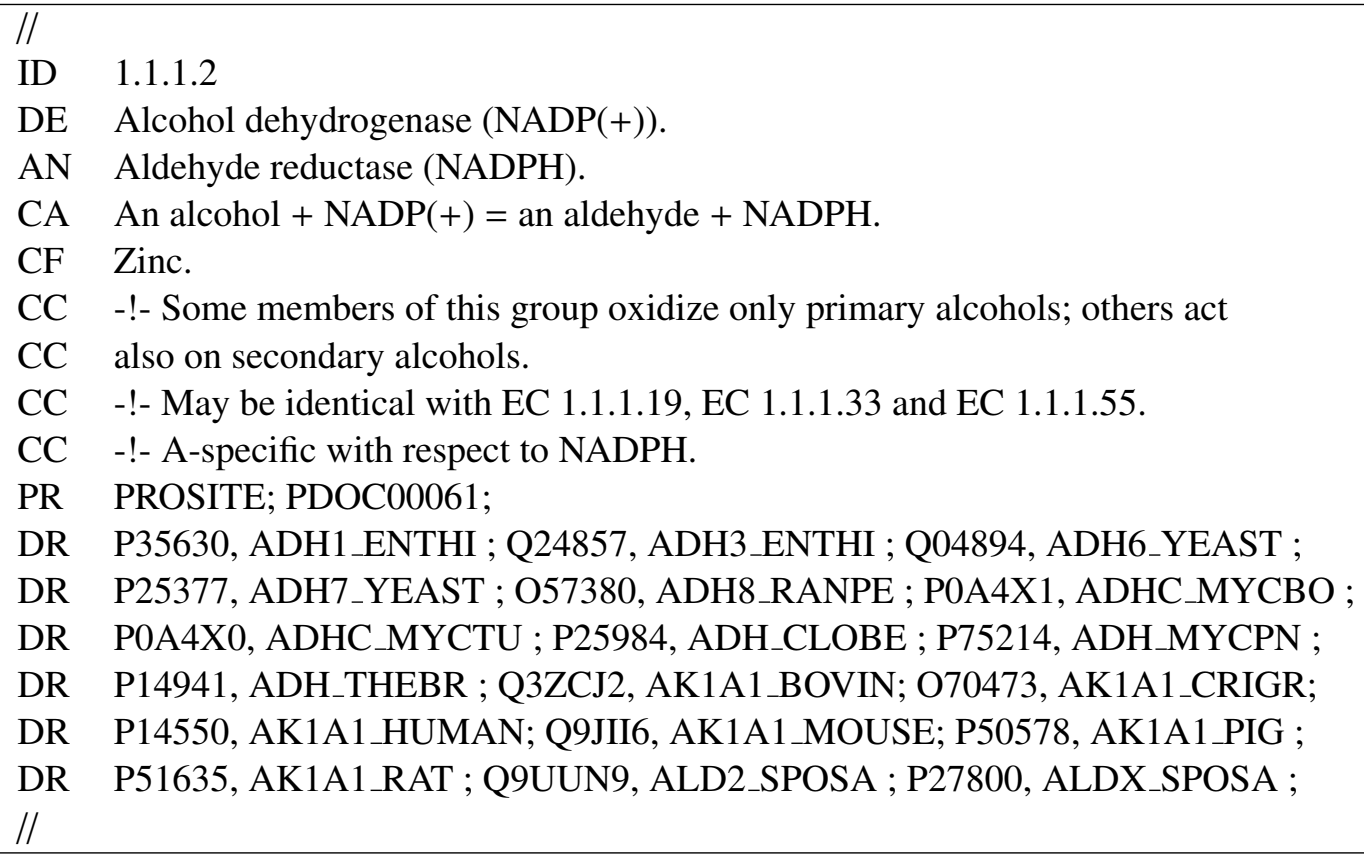

Table 3.2 shows the total number of enzymes assigned to six major enzyme classes and number of sub-classes of these classes at the lower levels. For example, oxidoreductases have 21 sub-classes at the second-level, 85 sub-subclasses at the third level, 617 sub-sub-subclasses at the fourth-level and in total 28539 enzymes assigned to the sub-sub-subclasses.

Table 3.2: First-level EC classes and their related information.

\begin{tabular}{|c|c|c|c|c|}
\hline \multirow[b]{2}{*}{ EC class } & \multicolumn{3}{|c|}{ number of sub-classes at level } & \multirow[b]{2}{*}{ total number of proteins } \\
\hline & 2 & 3 & 4 & \\
\hline 1 Oxidoreductases & 21 & 85 & 617 & 28539 \\
\hline 2 Transferases & 9 & 31 & 686 & 49425 \\
\hline 3 Hydrolases & 11 & 49 & 730 & 29890 \\
\hline 4 Lyases & 7 & 15 & 221 & 14264 \\
\hline 5 Isomerases & 6 & 17 & 103 & 8225 \\
\hline 6 Ligases & 6 & 10 & 97 & 18336 \\
\hline Total & 60 & 207 & 2454 & 148679 \\
\hline
\end{tabular}




\subsubsection{Data Preparation for the First-Level Classification}

There are 6 major EC classes at the first level of the hierarchy. To prepare positive and negative training datasets for each of these 6 classes, positive samples are extracted from the target EC class and negative samples are extracted from the remaining five EC classes.

Figure 3.1 is a sample representation of the tree structure showing the positive and negative EC classes selected to prepare the training datasets for a first-level target EC class, EC 1 (oxidoreductases).

Positive datasets for each fold of the 5-fold cross-validation are prepared by selecting enzymes from the sub-sub-subclasses of EC 1 and negative datasets are prepared by selecting representative enzymes from the sub-sub-subclasses of remaining 5 major EC classes.

Algorithm 1 is used to prepare positive datasets for each fold of the 5-fold cross-validation. The classification performance would be comparable if every fold contains enzymes from each sub-sub-subclass of the target EC class. Therefore, for each target EC class $p$, for each sub-sub-subclass having size enzymes, if size is more than five, size/5 of the enzymes are added to each fold. If size is less than five, these enzymes are added to the temporary set tempprots. After selecting enzymes from all of the sub-sub-subclasses, 1/5 of the enzymes in tempprots are added to each fold. 


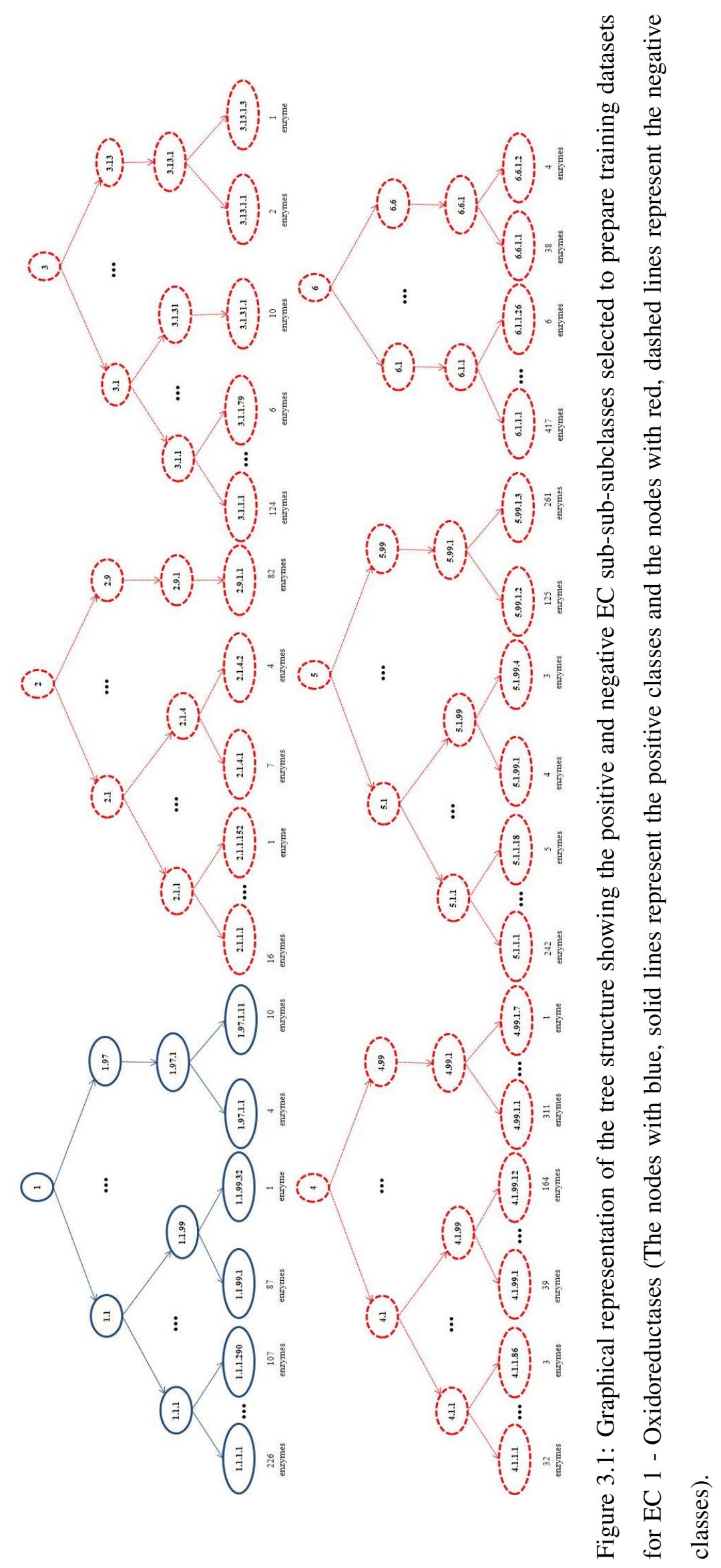




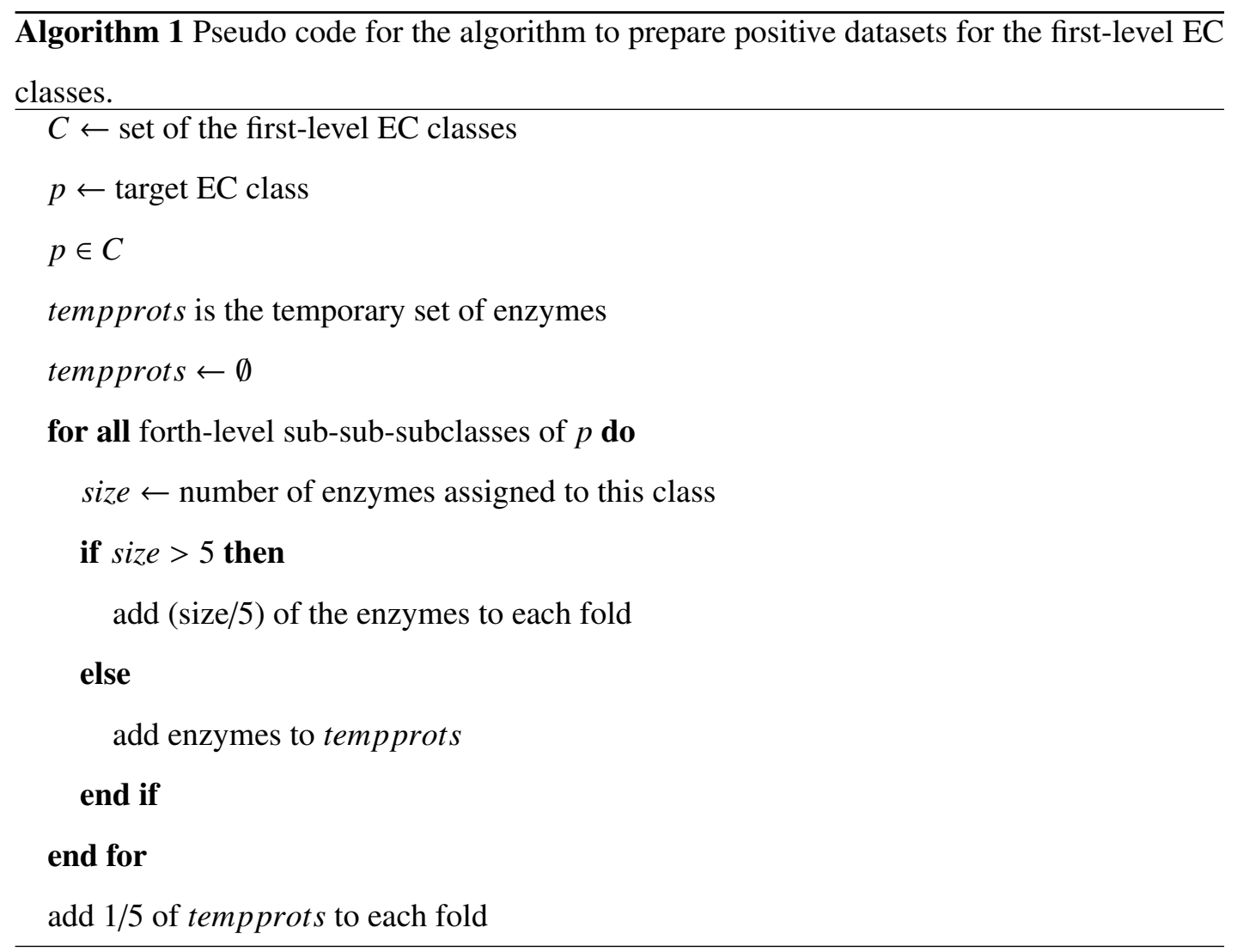

Algorithm 2 is used to prepare negative datasets for each fold of the 5-fold cross-validation. For each target EC class $p$, enzymes from the remaining five EC classes $N$ are selected for the negative datasets. However, if all the enzymes from the negative classes were selected, the total number of enzymes in the negative datasets would be much more than the enzymes in the positive datasets, which will cause an imbalance between the datasets. Therefore, for the sub-sub-subclasses having more than 25 enzymes, $1 / 3$ of the enzymes are selected and $1 / 5$ of these enzymes are added to each fold. Otherwise, if the size of the enzymes is more than five, size/5 of the proteins are added to each fold, if size is less than five, the enzymes are added to tempprots. After selecting all enzymes, 1/5 of the enzymes in tempprots are added to each fold. By doing this, the negative training dataset consists representative samples from all of the sub-sub-subclasses at the fourth-level. 


\subsubsection{Data Preparation for the Second-Level Classification}

Table 3.3 shows the second-level EC sub-classes and number of proteins in each second-level sub-class.

Table 3.3: Second-Level EC sub-classes and number of proteins.

\begin{tabular}{|c|c|c|}
\hline \multicolumn{3}{|c|}{ EC 1 Oxidoreductases } \\
\hline sub-class & Name & number of proteins \\
\hline EC 1.1 & Acting on the $\mathrm{CH}-\mathrm{OH}$ group & 6047 \\
\hline EC 1.2 & Acting on the aldehyde or oxo group of donors & 2483 \\
\hline EC 1.3 & Acting on the $\mathrm{CH}-\mathrm{CH}$ group of donors & 1589 \\
\hline EC 1.4 & Acting on the $\mathrm{CH}-\mathrm{NH}_{2}$ group of donors & 1121 \\
\hline EC 1.5 & Acting on the $\mathrm{CH}-\mathrm{NH}$ group of donors & 6618 \\
\hline EC 1.6 & Acting on NADH or NADPH & 3248 \\
\hline EC 1.7 & Acting on other nitrogenous compounds as donors & 718 \\
\hline EC 1.8 & Acting on a sulfur group of donors & 953 \\
\hline EC 1.9 & Acting on a heme group of donors & 588 \\
\hline EC 1.10 & Acting on diphenols and related substances as donors & 190 \\
\hline EC 1.11 & Acting on a peroxide as acceptor & 1370 \\
\hline EC 1.12 & Acting on hydrogen as donor & 83 \\
\hline EC 1.13 & $\begin{array}{l}\text { Acting on single donors with incorporation } \\
\text { of molecular oxygen (oxygenases) }\end{array}$ & 609 \\
\hline EC 1.14 & $\begin{array}{l}\text { Acting on paired donors, with incorporation } \\
\text { or reduction of molecular oxygen }\end{array}$ & 1214 \\
\hline EC 1.15 & Acting on superoxide radicals as acceptor & 426 \\
\hline EC 1.16 & Oxidising metal ions & 110 \\
\hline EC 1.17 & Acting on $\mathrm{CH}$ or $\mathrm{CH}_{2}$ groups & 814 \\
\hline EC 1.18 & Acting on iron-sulfur proteins as donors & 208 \\
\hline EC 1.20 & Acting on phosphorus or arsenic in donors & 16 \\
\hline EC 1.21 & Acting on $\mathrm{X}-\mathrm{H}$ and $\mathrm{Y}-\mathrm{H}$ to form an $\mathrm{X}-\mathrm{Y}$ bond & 71 \\
\hline EC 1.97 & Other oxidoreductases & 63 \\
\hline
\end{tabular}


Table 3.3 - Continued

\begin{tabular}{|c|c|c|}
\hline \multicolumn{3}{|c|}{ EC 2 Transferases } \\
\hline sub-class & Name & number of proteins \\
\hline EC 2.1 & Transferring one-carbon groups & 6740 \\
\hline EC 2.2 & Transferring aldehyde or ketonic groups & 1032 \\
\hline EC 2.3 & Acyltransferases & 4457 \\
\hline EC 2.4 & Glycosyltransferases & 5817 \\
\hline EC 2.5 & $\begin{array}{l}\text { Transferring alkyl or aryl groups, other } \\
\text { than methyl groups }\end{array}$ & 4156 \\
\hline EC 2.6 & Transferring nitrogenous groups & 1582 \\
\hline EC 2.7 & Transferring phosphorus-containing groups & 24629 \\
\hline EC 2.8 & Transferring sulfur-containing groups & 930 \\
\hline EC 2.9 & Transferring selenium-containing groups & 82 \\
\hline \multicolumn{3}{|c|}{ EC 3 Hydrolases } \\
\hline sub-class & Name & number of proteins \\
\hline EC 3.1 & Acting on ester bonds & 9480 \\
\hline EC 3.2 & Glycosylases & 2551 \\
\hline EC 3.3 & Acting on ether bonds & 255 \\
\hline EC 3.4 & Acting on peptide bonds (peptidases) & 4999 \\
\hline EC 3.5 & $\begin{array}{l}\text { Acting on carbon-nitrogen bonds, other } \\
\text { than peptide bonds }\end{array}$ & 5720 \\
\hline EC 3.6 & Acting on acid anhydrides & 6708 \\
\hline EC 3.7 & Acting on carbon-carbon bonds & 89 \\
\hline EC 3.8 & Acting on halide bonds & 41 \\
\hline EC 3.10 & Acting on sulfur-nitrogen bonds & 1 \\
\hline EC 3.11 & Acting on carbon-phosphorus bonds & 43 \\
\hline EC 3.13 & Acting on carbon-sulfur bonds & 3 \\
\hline
\end{tabular}


Table 3.3 - Continued

\begin{tabular}{|l|l|r|}
\hline \multicolumn{2}{|c|}{ EC 4 Lyases } \\
\hline sub-class & Name & number of proteins \\
\hline EC 4.1 & Carbon-carbon lyases & 5082 \\
\hline EC 4.2 & Carbon-oxygen lyases & 6881 \\
\hline EC 4.3 & Carbon-nitrogen lyases & 944 \\
\hline EC 4.4 & Carbon-sulfur lyases & 386 \\
\hline EC 4.5 & Carbon-halide lyases & 2 \\
\hline EC 4.6 & Phosphorus-oxygen lyases & 520 \\
\hline EC 4.99 & Other lyases & 449 \\
\hline & & number of proteins \\
\hline sub-class & Name & 1381 \\
\hline EC 5.1 & Racemases and epimerases & 689 \\
\hline EC 5.2 & cis-trans-Isomerases & 3307 \\
\hline EC 5.3 & Intramolecular isomerases & 2358 \\
\hline EC 5.4 & Intramolecular transferases(mutases) & 104 \\
\hline EC 5.5 & Intramolecular lyases & number of proteins \\
\hline EC 5.99 & Other isomerases & 9505 \\
\hline & & 386 \\
\hline sub-class & Name & 6585 \\
\hline EC 6.1 & Forming carbon-oxygen bonds & 649 \\
\hline EC 6.2 & Forming carbon-sulfur bonds & 747 \\
\hline EC 6.3 & Forming carbon-nitrogen bonds & 42 \\
\hline EC 6.4 & Forming carbon-carbon bonds & \\
\hline EC 6.5 & Forming phosphoric ester bonds & \\
\hline EC 6.6 & Forming nitrogen-metal bonds & Eigases \\
\hline
\end{tabular}

In the second-level, there are 60 sub-classes. EC 3.10, EC 3.13 and EC 4.5 sub-classes don't have sufficient number of enzymes, therefore positive and negative datasets are prepared for 57 sub-classes.

The algorithms used to prepare positive and negative datasets for the second-level sub-classes 
are similar to the ones explained at the first-level data preparation. The difference from the first-level is that, in the first-level classification, $1 / 3$ of the enzymes are selected from the negative classes, but in the second-level classification all of the enzymes in the negative sub-classes are used to prepare the negative datasets. At the second-level, one second-level sub-class of a first-level class is used as the target sub-class, and the remaining second-level sub-classes of the same class are used to prepare the negative datasets for the target sub-class. For example, Oxidoreductases has 21 sub-classes at the second-level. For the target class, EC 1.1, the positive datasets are prepared using this sub-class and the negative datasets are prepared using the remaining 20 sub-classes of oxidoreductases. Figure 3.2 shows the positive and negative EC sub-sub-subclasses selected to prepare training datasets for EC 1.1 (Oxidoreductases acting on the $\mathrm{CH}-\mathrm{OH}$ group), on the tree structure. Algorithm 3 is the pseudo code for the algorithm to prepare positive datasets for the second-level EC sub-classes and Algorithm 4 is the pseudo code for the algorithm to prepare negative datasets for the second-level EC sub-classes.

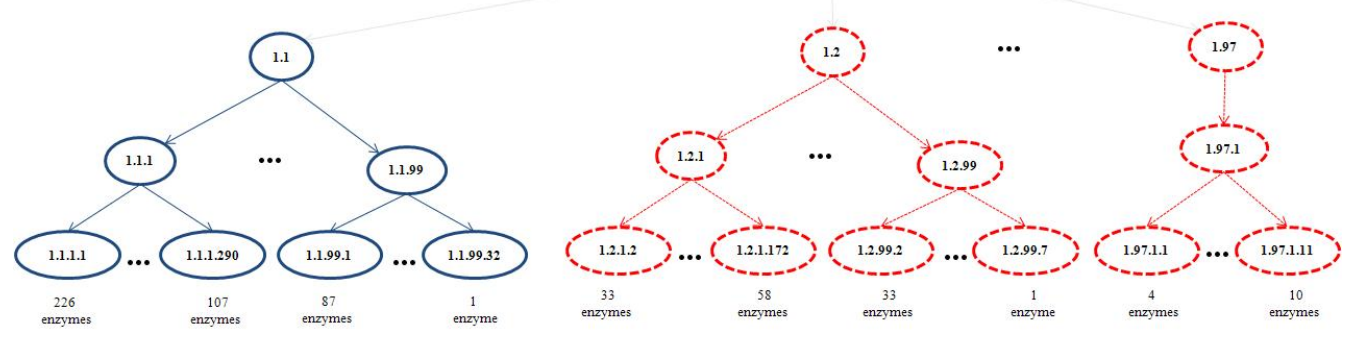

Figure 3.2: Graphical representation of the tree structure showing the positive and negative EC sub-sub-subclasses selected to prepare training datasets for EC 1.1 - Oxidoreductases acting on the $\mathrm{CH}-\mathrm{OH}$ group (The nodes with blue, solid lines represent the positive classes and the nodes with red, dashed lines represent the negative classes). 


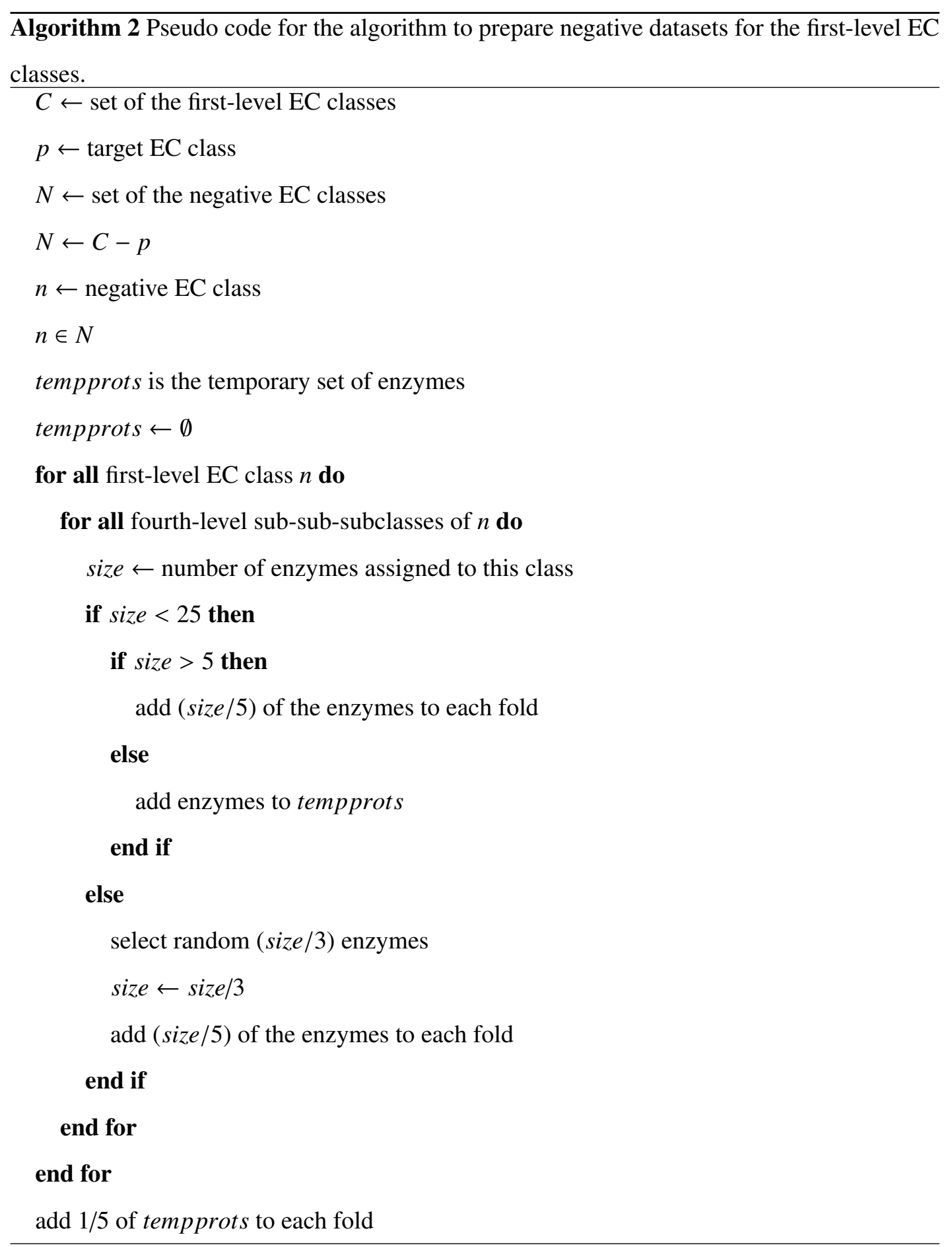




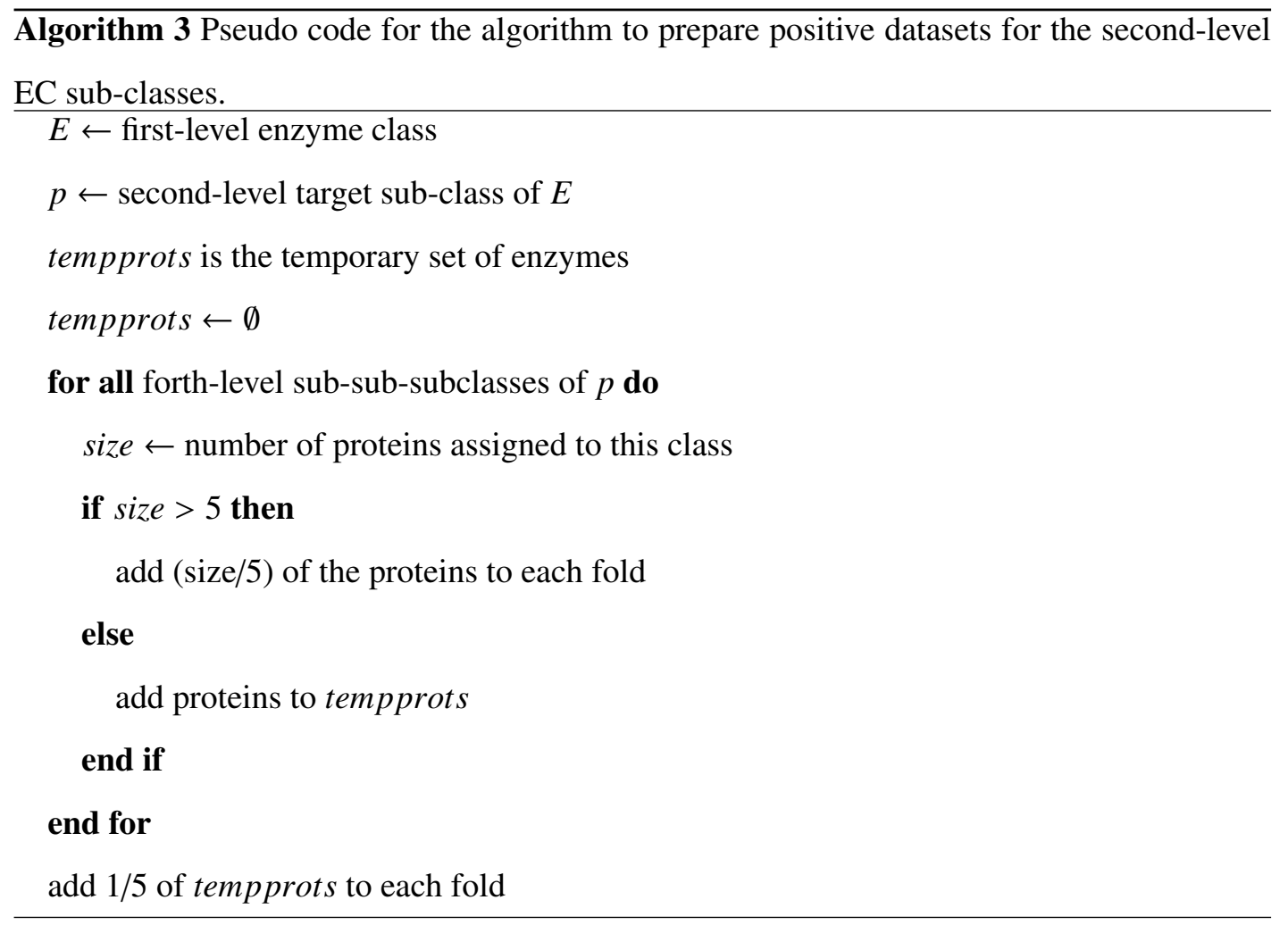




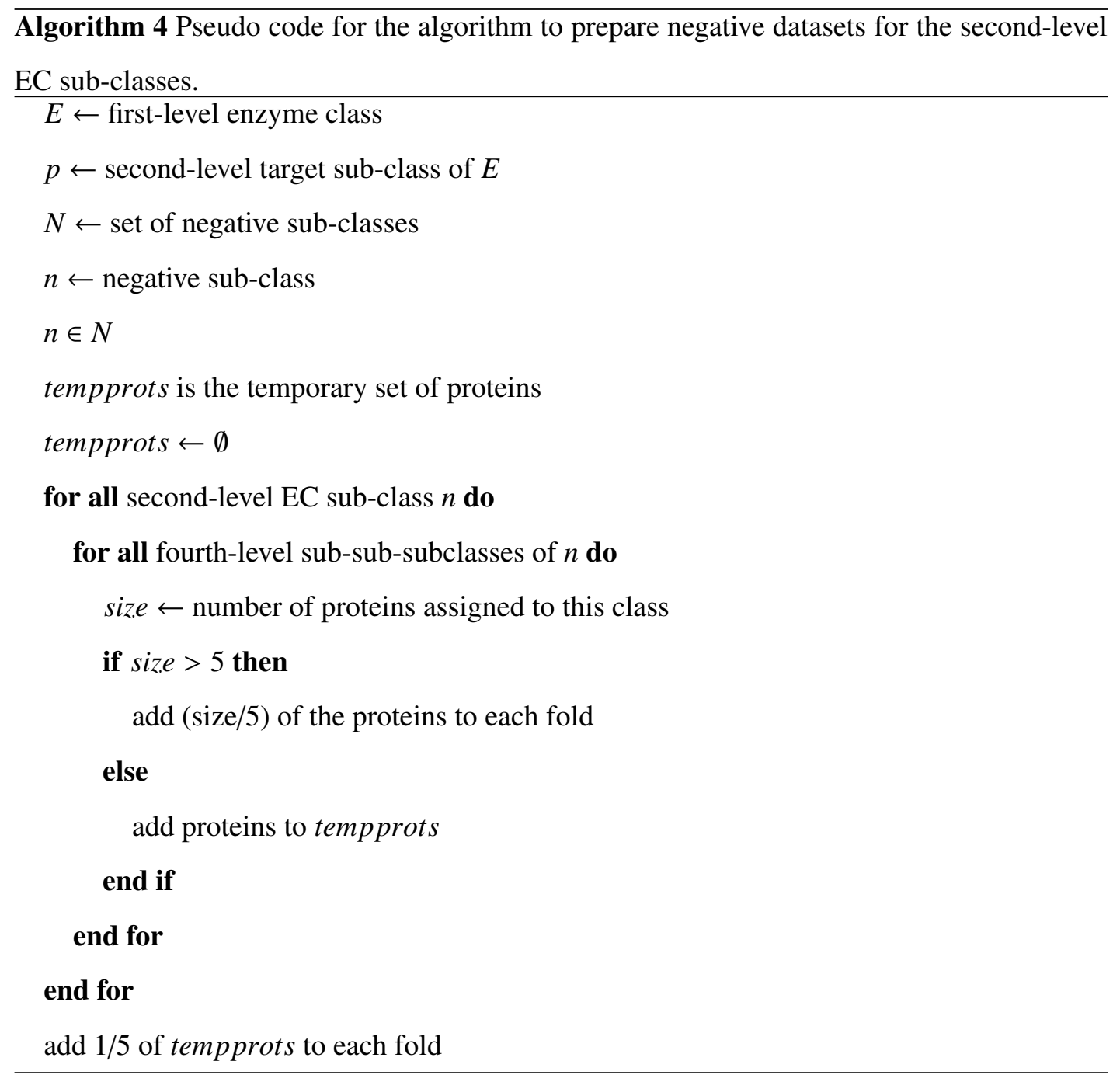




\subsubsection{Data Preparation for the Third-Level Classification}

There are 207 sub-sub-subclasses at the third-level of the hierarchical tree structure of the Enzyme Commission classes. The sub-classes EC 1.9, EC 1.11, EC 1.15, EC 1.97, EC 2.2, EC 2.5, EC 2.9, EC 3.7, EC 3.8, EC 3.11, EC 4.4, EC 4.6, EC 4.99, EC 5.2, EC 5.5, EC 5.99, EC 6.1, EC 6.2, EC 6.4, EC 6.5 and EC 6.6 have only one sub-subclass at the third level, therefore it is redundant to perform classification for the sub-subclasses of these sub-classes at the third-level again. Positive and negative datasets are prepared for 140 sub-subclasses from the remaining 186 classes, which have sufficient number of enzymes to train the classifiers. The same algorithm explained for the second-level data preparation is applied to prepare the datasets at the third-level. Figure 3.3 shows the positive and negative EC sub-sub-subclasses selected to prepare training datasets for an example sub-subclass, EC 1.1.1 (Oxidoreductases acting on the $\mathrm{CH}-\mathrm{OH}$ group with NAD or NADP as acceptor), on the tree structure.

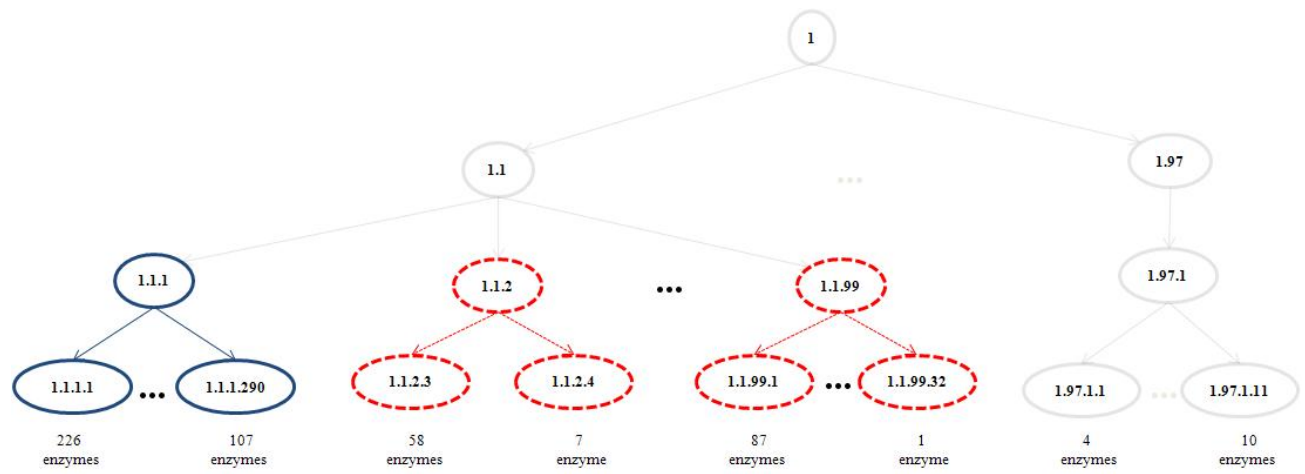

Figure 3.3: Graphical representation of the tree structure showing the positive and negative EC sub-sub-subclasses selected to prepare training datasets for EC 1.1.1 - Oxidoreductases acting on the $\mathrm{CH}-\mathrm{OH}$ group with NAD or NADP as acceptor (The nodes with blue, solid lines represent the positive classes and the nodes with red, dashed lines represent the negative classes). 


\subsection{METHODS}

Subsequence Profile Map (SPMap) [35] is used for feature extraction and Support Vector Machines (SVM) [22] are used for classification.

\subsubsection{SPMap}

SPMap is a subsequence-based feature extraction method which uses all fixed-length subsequences in the training dataset to construct a probabilistic profile map and calculates the feature values forms feature vector of each protein according to these profiles. There are 4 steps for feature extraction in SPMap.

- Subsequence Extraction : In the first step, all fixed length subsequences of proteins in the training dataset are extracted.

- Clustering : In the second step, similar subsequences are clustered.

- Probabilistic Profile Matrix Construction : In the third step, a probabilistic profile matrix is constructed for each cluster.

- Feature Vector Generation : In the fourth step, feature vectors of each protein in the training dataset are constructed.

Figure 3.4 shows these steps.

\section{Subsequence Extraction}

Conserved subsequences of proteins called motifs are known to have important role on identifying the functions of proteins, because rather than other parts of sequences, regions such as catalytic sites and binding sites are conserved over much wider taxonomic distances [7]. There are several motif and domain databases such as PROSITE [27], BLOCKS [26], PRINTS [4], InterPro [2], Pfam [6] and ProDom [20] that are used to construct feature vectors. In SPMap, instead of using motifs or domains from these databases, fixed length subsequences are extracted from the training datasets of protein sequences and information coming from these subsequences is used to generate the feature vectors. 


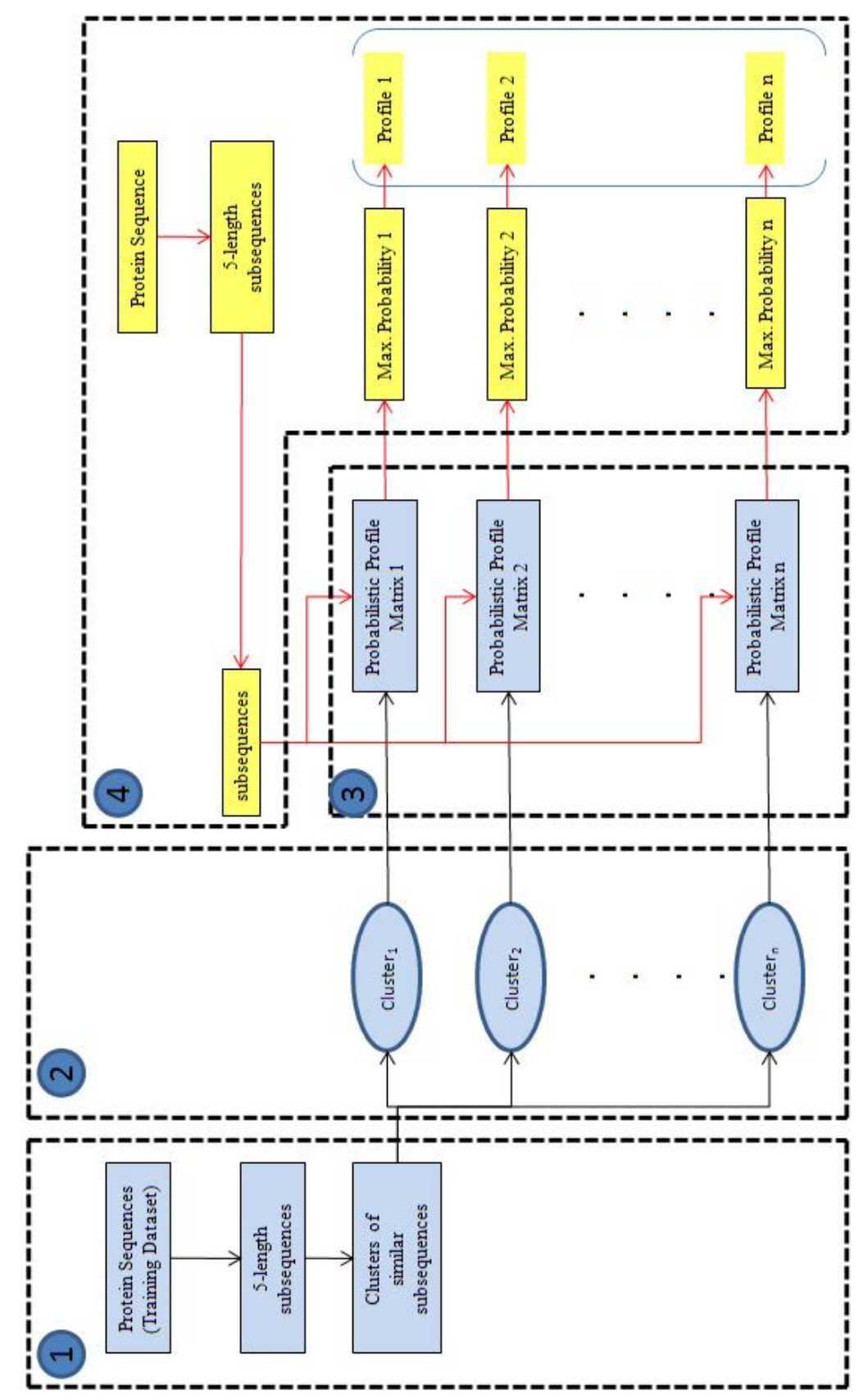

Figure 3.4: Steps and general flow of SPMap. 1) Subsequence extraction. 2) Clustering. 3) Probabilistic profile matrix construction. 4) Feature vector generation. 


\section{Clustering}

Clustering is the crucial part of SPMap method. The flowchart of the clustering algorithm used in SPMap is shown in Figure 3.5.

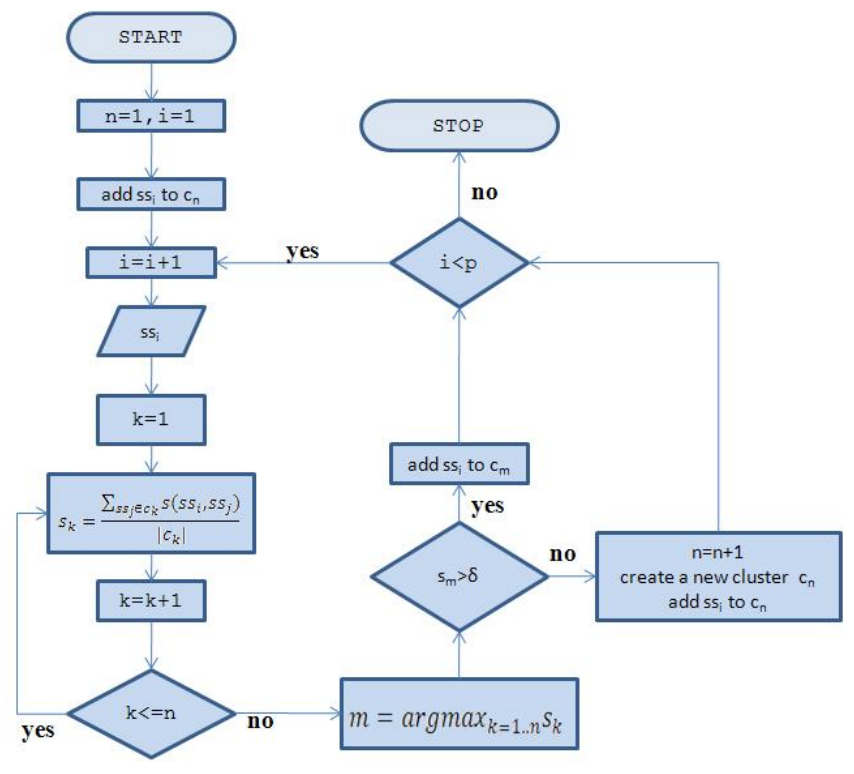

Figure 3.5: Flowchart of the clustering algorithm.

After the extraction of 5-length subsequences from the training dataset, these subsequences are clustered according to the similarity among them. Initially, the first subsequence, $s s_{1}$, is added to the first cluster, $c_{1}$. Then each subsequence, $s s_{i}$, is compared with the subsequences in all clusters, $c_{k}, k: 1, \ldots, n$. The average similarity, $a v g_{k}$, between the subsequence, $s s_{i}$ and the subsequences in cluster, $c_{k}$, is calculated by the formula,

$$
a v g_{k}=\frac{\sum_{s s_{j} \in c_{k}} s\left(s s_{i}, s s_{j}\right)}{\left|c_{k}\right|}
$$

where $s\left(s s_{i}, s s j\right)$ is the similarity between two subsequences, $s s_{i}$ and $s s_{j}$. The similarity matrix, Blosum62, shown in Figure 3.6 is used while calculating the similarity between two subsequences. For the 5-length two subsequences, $x$ and $y$, the similarity between them is the sum of the similarity values of amino acids at each position of the subsequences, in Blosum62 matrix as given in Equation 3.2. 


$$
s(x, y)=\sum_{i=1}^{5} M(x(i), y(i))
$$

For example, for two subsequences,

$s s_{1}=" M T K G I "$ and $s s_{2}=" M K N K S "$, the similarity between them is

$$
\begin{aligned}
s\left(s s_{1}, s s_{2}\right) & =M(M, M)+M(T, K)+M(K, N)+M(G, K)+M(I, S) \\
& =5+(-1)+0+(-2)+(-2) \\
& =0
\end{aligned}
$$

$\begin{array}{lrrrrrrrrrrrrrrrrrrrr} & \mathrm{A} & \mathrm{R} & \mathrm{N} & \mathrm{D} & \mathrm{C} & \mathrm{Q} & \mathrm{E} & \mathrm{G} & \mathrm{H} & \mathrm{1} & \mathrm{L} & \mathrm{K} & \mathrm{M} & \mathrm{F} & \mathrm{P} & \mathrm{S} & \mathrm{T} & \mathrm{W} & \mathrm{Y} & \mathrm{V} \\ \mathrm{A} & 4 & -1 & -2 & -2 & \mathrm{O} & -1 & -1 & \mathrm{O} & -2 & -1 & -1 & -1 & -1 & -2 & -1 & 1 & 0 & -3 & -2 & 0 \\ \mathrm{R} & -1 & 5 & \mathrm{O} & -2 & -3 & 1 & 0 & -2 & 0 & -3 & -2 & 2 & -1 & -3 & -2 & -1 & -1 & -3 & -2 & -3 \\ \mathrm{~N} & -2 & \mathrm{O} & 6 & \mathrm{1} & -3 & 0 & 0 & 0 & 1 & -3 & -3 & 0 & -2 & -3 & -2 & 1 & 0 & -4 & -2 & -3 \\ \mathrm{D} & -2 & -2 & 1 & 6 & -3 & 0 & 2 & -1 & -1 & -3 & -4 & -1 & -3 & -3 & -1 & 0 & -1 & -4 & -3 & -3 \\ \mathrm{C} & \mathrm{O} & -3 & -3 & -3 & 9 & -3 & -4 & -3 & -3 & -1 & -1 & -3 & -1 & -2 & -3 & -1 & -1 & -2 & -2 & -1 \\ \mathrm{Q} & -1 & 1 & 0 & 0 & -3 & 5 & 2 & -2 & 0 & -3 & -2 & 1 & 0 & -3 & -1 & 0 & -1 & -2 & -1 & -2 \\ \mathrm{E} & -1 & 0 & 0 & 2 & -4 & 2 & 5 & -2 & 0 & -3 & -3 & 1 & -2 & -3 & -1 & 0 & -1 & -3 & -2 & -2 \\ \mathrm{G} & 0 & -2 & 0 & -1 & -3 & -2 & -2 & 6 & -2 & -4 & -4 & -2 & -3 & -3 & -2 & 0 & -2 & -2 & -3 & -3 \\ \mathrm{H} & -2 & 0 & 1 & -1 & -3 & 0 & 0 & -2 & 8 & -3 & -3 & -1 & -2 & -1 & -2 & -1 & -2 & -2 & 2 & -3 \\ \mathrm{I} & -1 & -3 & -3 & -3 & -1 & -3 & -3 & -4 & -3 & 4 & 2 & -3 & 1 & 0 & -3 & -2 & -1 & -3 & -1 & 3 \\ \mathrm{~L} & -1 & -2 & -3 & -4 & -1 & -2 & -3 & -4 & -3 & 2 & 4 & -2 & 2 & 0 & -3 & -2 & -1 & -2 & -1 & 1 \\ \mathrm{~K} & -1 & 2 & 0 & -1 & -3 & 1 & 1 & -2 & -1 & -3 & -2 & 5 & -1 & -3 & -1 & 0 & -1 & -3 & -2 & -2 \\ \mathrm{M} & -1 & -1 & -2 & -3 & -1 & 0 & -2 & -3 & -2 & 1 & 2 & -1 & 5 & 0 & -2 & -1 & -1 & -1 & -1 & 1 \\ \mathrm{~F} & -2 & -3 & -3 & -3 & -2 & -3 & -3 & -3 & -1 & 0 & 0 & -3 & 0 & 6 & -4 & -2 & -2 & 1 & 3 & -1 \\ \mathrm{P} & -1 & -2 & -2 & -1 & -3 & -1 & -1 & -2 & -2 & -3 & -3 & -1 & -2 & -4 & 7 & -1 & -1 & -4 & -3 & -2 \\ \mathrm{~S} & \mathrm{1} & -1 & 1 & 0 & -1 & 0 & 0 & 0 & -1 & -2 & -2 & 0 & -1 & -2 & -1 & 4 & 1 & -3 & -2 & -2 \\ \mathrm{~T} & 0 & -1 & 0 & -1 & -1 & -1 & -1 & -2 & -2 & -1 & -1 & -1 & -1 & -2 & -1 & 1 & 5 & -2 & -2 & 0 \\ \mathrm{~W} & -3 & -3 & -4 & -4 & -2 & -2 & -3 & -2 & -2 & -3 & -2 & -3 & -1 & 1 & -4 & -3 & -2 & 11 & 2 & -3 \\ \mathrm{Y} & -2 & -2 & -2 & -3 & -2 & -1 & -2 & -3 & 2 & -1 & -1 & -2 & -1 & 3 & -3 & -2 & -2 & 2 & 7 & -1 \\ \mathrm{~V} & 0 & -3 & -3 & -3 & -1 & -2 & -2 & -3 & -3 & 3 & 1 & -2 & 1 & -1 & -2 & -2 & 0 & -3 & -1 & 4\end{array}$

Figure 3.6: Blosum62 amino acid similarity matrix [25].

After calculating the average similarity values for all clusters, the subsequence is added to the cluster, $c_{m}$, with the maximum average similarity value, $a v g_{m}$, if this value is greater than the threshold value, $\delta$. Otherwise, a new cluster, $c_{n+1}$, is created and the subsequence, $s s_{i}$, is added to this cluster. The threshold value is important because the number of clusters, $n$, depends on the threshold value, $\delta$. A small threshold value will cause dissimilar subsequences fall into the same cluster. On the other hand, the number of clusters, hence the dimension of the feature space will increase with a high threshold value. In this study, the threshold value $\delta$ is chosen as 8 . 


\section{Probabilistic Profile Matrix Construction}

The third step of the SPMap method is the generation of probabilistic profiles from the clusters created in the second step. For each cluster, $c_{k}$, a probabilistic profile, $P P_{k}$-a matrix with $5 \times 20$ dimensions- is generated, where 5 is the length of the subsequences and 20 is the number of amino acids. Each $(i, j)$ th entry of the probabilistic profile, $P P_{k}$, is calculated by Equation 3.3 where $\phi_{k}(i, j)$ is the count of the $j$ th amino acid at $i$ th position of all of the subsequences in cluster, $c_{k} . \kappa$ is used to overcome overfitting and zero probability problems.

$$
P P_{k}(i, j)=\log \frac{\phi_{k}(i, j)+\kappa}{\left|c_{k}\right|}
$$

\section{Feature Vector Generation}

The feature vector of an enzyme sequence is generated by distributing its subsequences over the subsequence profile map constructed in the clustering step. First, all 5-length subsequences of the enzyme sequence are extracted. Each of these subsequences are compared with the probabilistic profile, $P P_{k}$, created for each cluster, $c_{k}$ and a probability is calculated based on Equation 3.4.

$$
P\left(s s \mid P P_{k}\right)=\sum_{i=0}^{5} P P_{k}(i, s s(i))
$$

Here, the probability of the subsequence $s s$ to appear in cluster $c_{k}$ is the sum of the probabilistic profile values for $i$ th amino acid of $s s$ at the $i$ th position of all subsequences in cluster $c_{k}$.

The dimension of the feature vector, $V$, of an enzyme sequence is equal to the number of clusters. Each $k$ th value of $\mathrm{V}$ is the probability of the subsequence of enzyme $\mathrm{S}$ with the highest score on the probabilistic profile $P P_{k}$ defined by:

$$
V(k)=\max _{s s_{i} \in S} P\left(s s_{i} \mid P P_{k}\right)
$$

If the probability is very small, $k$ th value of the feature vector $\mathrm{V}(\mathrm{k})$ is set to zero. 


\subsubsection{Classification}

After generating the feature vectors from enzyme sequences in the training dataset, Support Vector Machines (SVMs) are applied to the enzyme classification problem. Radial Basis Function (RBF) is used as the kernel function for SVM. The SVM parameter $C$ and RBF kernel parameter $\gamma$ are set to 2 and 0.005 , respectively. SVM-light software by Joachims (1999) [28] is used to implement SVM.

Support Vector Machines are binary classifiers introduced by Vapnik [42, 43, 36].

The notation is adopted from Burges [10].

Let $l$ be the number of samples in the training dataset and $\mathbf{x}$ be the feature vectors representing these samples (in our case enzymes). The training data is labeled as follows:

$$
\left\{\mathbf{x}_{i}, y_{i}\right\}, \quad i=1, \ldots, l, \quad y_{i} \in\{-1,+1\}, \quad \mathbf{x}_{i} \in \mathfrak{R}^{d}
$$

where $\mathbf{x}_{i}$ is the vector representing the $i$ th sample and $y_{i}$ is the label of the sample indicating the class it belongs to ( +1 for positive and -1 for negative).

\subsubsection{Linear Support Vector Machines}

\section{Linear Separable SVM}

In the linear separable case (Figure 3.7), the goal of SVM is to find a hyperplane

$$
\mathbf{w} \cdot \mathbf{x}+b=0
$$

that separates the positive and negative samples, where

$\mathbf{w}$ : normal to the hyperplane,

$\frac{|b|}{\|\mathbf{w}\|}:$ the perpendicular distance from the hyperplane to the origin,

$\|\mathbf{w}\|$ : Euclidean norm of $\mathbf{w}$.

The decision function is $f(\mathbf{x})=\operatorname{sign}(\mathbf{w} \cdot \mathbf{x}+b)$. If $f(\mathbf{x})>0, \mathbf{x}$ is classified to the positive class $(y=+1)$, otherwise the negative class $(y=-1)$. 


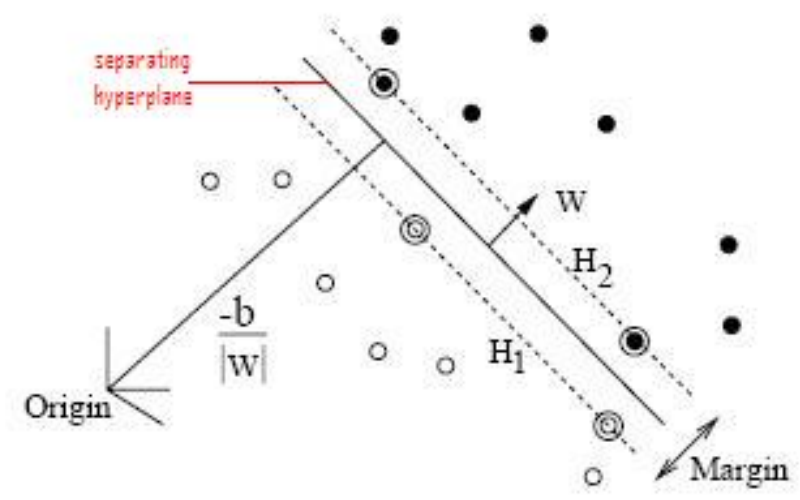

Figure 3.7: Linear separating hyperplanes for separable SVM. (Adopted from [10])

Let

$d_{+}$: the shortest distance from the separating hyperplane to the closest positive example,

$d_{-}$: the shortest distance from the separating hyperplane to the closest negative example,

$d_{+}+d_{-}:$the "margin" of the separating hyperplane.

The optimal hyperplane is the hyperplane that separates the positive samples from the negative samples with maximal margin. In order to maximize the margin, the separating hyperplane should satisfy the constraints

$$
\begin{array}{ll}
\mathbf{x}_{i} \cdot \mathbf{w}+b \geq+1 & \text { for } y_{i}=+1 \\
\mathbf{x}_{i} \cdot \mathbf{w}+b \leq-1 & \text { for } y_{i}=-1
\end{array}
$$

which can be combined into the inequality

$$
y_{i}\left(\mathbf{x}_{i} \cdot \mathbf{w}+b\right)-1 \leq 0 \quad \forall i
$$

The two hyperplanes $H_{1}$ and $H_{2}$, where the closest positive and negative data points lie on are

$$
H_{1}=\mathbf{x}_{i} \cdot \mathbf{w}+b=1
$$

and

$$
H_{2}=\mathbf{x}_{i} \cdot \mathbf{w}+b=-1
$$

where $\mathbf{w}$ is the normal, $|1-b| /\|\mathbf{w}\|$ is the perpendicular distance of $H_{1}$ from the origin, | $1-b \mid /\|\mathbf{w}\|$ is the perpendicular distance of $H_{2}$ from the origin and $2 /\|\mathbf{w}\|$ is the margin of the 
separating hyperplane (the distance between $H_{1}$ and $H_{2}$ ). In order to maximize the margin the optimization problem

$$
\min _{\mathbf{w}, b} \frac{1}{2}\|\mathbf{w}\|^{2}
$$

should be solved, subject to the constraints in Equation 3.9. The points that lie on $H_{1}, H_{2}$ (indicated by circles in Figure 3.7) and satisfy these constraints are called support vectors.

Now, the problem of constructing an optimal separating hyperplane turns into a convex quadratic problem. Lagrange multipliers $\alpha_{i}>0$ are introduced to solve this problem. The Lagrangian formulation of the minimization problem is

$$
\min _{\mathbf{w}, b, \alpha} L_{P} \equiv \frac{1}{2}\|\mathbf{w}\|^{2}-\sum_{i=1}^{l} \alpha_{i}\left(y_{i}\left(\mathbf{x}_{i} \cdot \mathbf{w}+b\right)-1\right)
$$

with respect to $\mathbf{w}$ and $b$, subject to constraints

$$
\begin{gathered}
\mathbf{w}=\sum_{i=1}^{l} \alpha_{i} y_{i} \mathbf{x}_{i} \\
\sum_{i=1}^{l} \alpha_{i} y_{i}=0
\end{gathered}
$$

where $\alpha_{i}, i=1, \ldots, l$ are the Lagrange multipliers for inequality constraints in Equation 3.9.

The problem is transformed into its dual optimization problem of maximizing $L_{D}$,

$$
\max _{\alpha} L_{D}=\sum_{i=1}^{l} \alpha_{i}-\frac{1}{2} \sum_{i, j=1}^{l} \alpha_{i} \alpha_{j} y_{i} y_{j} \mathbf{x}_{i} \mathbf{x}_{j}
$$

with respect to $\alpha_{i}$, subject to the constraints

$$
\begin{gathered}
\sum_{i=1}^{l} \alpha_{i} y_{i}=0 \\
\alpha_{i} \geq 0, \quad i=1, \ldots, l
\end{gathered}
$$

The optimal separating hyperplane is found by solving the quadratic programming problem, $L_{D}$ subject to the inequality constraints 3.17 and 3.18. In the solution, the points that lie on $H_{1}$ and $H_{2}$ with $\alpha_{i}>0$ are called support vectors. Support vectors satisfy the constraints 3.9 and lie closest to the separating hyperplane. For the remaining points, $\alpha_{i}=0$, therefore if these points were removed from the training datasets the optimal separating hyperplane would not change. 
The decision function is

$$
f(\mathbf{x})=\operatorname{sign}\left(\sum_{i=1}^{l} \alpha_{i} y_{i}\left(\mathbf{x} \cdot \mathbf{x}_{i}\right)\right)
$$

where $f(\mathbf{x})>0$ means that $\mathbf{x}$ is classified to the positive class, otherwise $\mathbf{x}$ is classified to the negative class.

\section{Linear Non-separable SVM}

In most of real life classification problems, the training data points are not linearly separable (Figure 3.8), therefore "soft margin classifiers" are introduced.

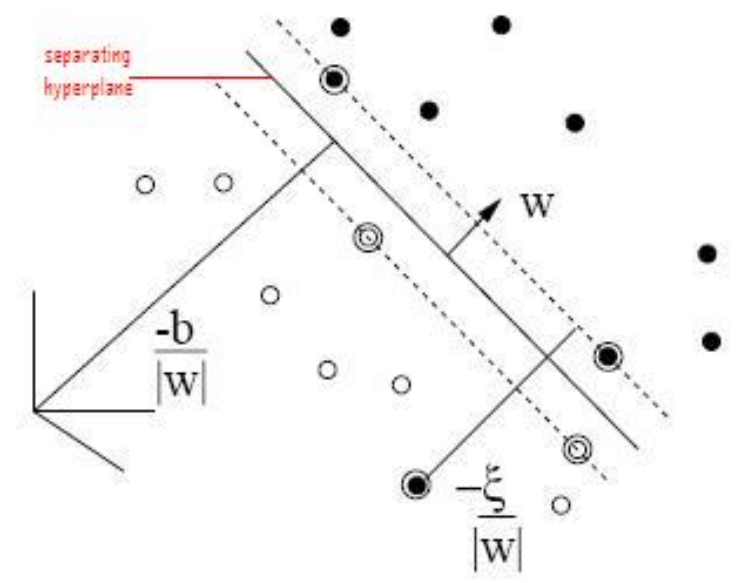

Figure 3.8: Linear separating hyperplanes for non-separable SVM. (Adopted from [10])

In this case, linear SVM is extended to non-separable SVM by introducing slack variables, $\xi_{i}, i=1, \ldots, l$ to relax the hard-margin constraints in Equations 3.7 and 3.8 into :

$$
\begin{array}{ll}
\mathbf{x}_{i} \cdot \mathbf{w}+b \geq+1-\xi_{i} & \text { for } y_{i}=+1 \\
\mathbf{x}_{i} \cdot \mathbf{w}+b \leq-1+\xi_{i} & \text { for } y_{i}=-1
\end{array}
$$

with an additional constraint

$$
\xi_{i} \geq 0 \quad \forall i
$$

The values of $\xi_{i}$ indicate which side of the separating hyperplane, the training data point, $\mathbf{x}_{i}$ lies. $\xi_{i} \geq 0$, if $\mathbf{x}_{i}$ is misclassified and lies on the wrong side of the hyperplane, therefore 
$\sum_{i=1}^{l} \xi_{i}$ is an upper bound on the number of training errors. $\xi_{i}=0$, if $\mathbf{x}_{i}$ is classified correctly, lies on or outside the correct margin. $0<\xi_{i}<1$, if $\mathbf{x}_{i}$ is classified correctly, but lies inside the margin.

The Lagrange formulation of the minimization problem becomes

$$
\min _{\mathbf{w}, b, \xi} L_{P} \equiv \frac{1}{2}\|\mathbf{w}\|^{2}+C \sum_{i=1}^{l} \xi_{i}
$$

where $C$ is a regularization parameter used to control the relation between the slack variables and $\|\mathbf{w}\|$.

The problem is transformed into its dual optimization problem of maximizing $L_{D}$,

$$
\max _{\alpha} L_{D}=\sum_{i} \alpha_{i}-\frac{1}{2} \sum_{i, j=1}^{l} \alpha_{i} \alpha_{j} y_{i} y_{j} \mathbf{x}_{i} \mathbf{x}_{j}
$$

with respect to $\alpha_{i}$, subject to the constraints

$$
\begin{aligned}
& 0 \leq \alpha_{i} \leq C \\
& \sum_{i=1}^{l} \alpha_{i} y_{i}=0
\end{aligned}
$$

The difference from the linear separable case is the upper bound $C$ on the Lagrange multipliers $\alpha_{i}$. The support vectors are training data points that lie on the separating hyperplane, as well as the data points between the two hyperplanes $H_{1}$ and $H_{2}$ or data points that lie on the wrong side of the separating hyperplane.

\subsubsection{Nonlinear Support Vector Machines}

In some cases, the decision boundary between the positive and negative training data is not linear. Thus, the input data is mapped into a higher dimensional feature space where it is linearly separable through a nonlinear function

$$
\Phi: \mathfrak{R}^{d} \rightarrow \mathcal{H}
$$

To overcome the problem of finding optimal separating hyperplane in the higher dimensional feature space, the "kernel trick" can be used. The dual Lagrange formulation in Equation 
3.24, contains the training data points in the form of Euclidean dot products $\mathbf{x}_{i} \cdot \mathbf{x}_{j}$. The dot product can be substituted into the higher dimensional feature space by

$$
\mathbf{x}_{i} \cdot \mathbf{x}_{j} \rightarrow \Phi\left(\mathbf{x}_{i}\right) . \Phi\left(\mathbf{x}_{j}\right)
$$

Instead of calculating this mapping explicitly, the function $K\left(\mathbf{x}_{i}, \mathbf{x}_{j}\right)=\Phi\left(\mathbf{x}_{i}\right) . \Phi\left(\mathbf{x}_{j}\right)$, called kernel function can be used.

Now, the optimization problem in Equation 3.24 becomes $L_{D}$,

$$
\max _{\alpha} L_{D}=\sum_{i} \alpha_{i}-\frac{1}{2} \sum_{i, j=1}^{l} \alpha_{i} \alpha_{j} y_{i} y_{j} K\left(\mathbf{x}_{i}, \mathbf{x}_{j}\right)
$$

subject to the same constraints

$$
\begin{aligned}
& 0 \leq \alpha_{i} \leq C \\
& \sum_{i=1}^{l} \alpha_{i} y_{i}=0
\end{aligned}
$$

When the optimization problem is solved, the decision function becomes

$$
f(\mathbf{x})=\operatorname{sign}\left(\sum_{i=1}^{l} \alpha_{i} y_{i} K\left(\mathbf{x}, \mathbf{x}_{i}\right)\right)
$$

where $f(\mathbf{x})>0$ means that $\mathbf{x}$ is classified to the positive class, otherwise $\mathbf{x}$ is classified to the negative class.

Some commonly used kernel functions are shown in Table 3.4.

Table 3.4: Kernel functions used for nonlinear SVMs.

\begin{tabular}{|l|l|}
\hline Linear & $K\left(\mathbf{x}_{i}, \mathbf{x}_{j}\right)=\left(\mathbf{x}_{i} \cdot \mathbf{x}_{j}\right)$ \\
\hline Polynomial & $K\left(\mathbf{x}_{i}, \mathbf{x}_{j}\right)=\left(\gamma \mathbf{x}_{i} \cdot \mathbf{x}_{j}+r\right)^{d}$ \\
\hline RBF & $K\left(\mathbf{x}_{i}, \mathbf{x}_{j}\right)=e^{\frac{-\gamma \mid\left\|_{i}-\mathbf{x}_{j}\right\|^{2}}{\sigma^{2}}}$ \\
\hline Sigmoid & $K\left(\mathbf{x}_{i}, \mathbf{x}_{j}\right)=\tanh \left(\gamma \mathbf{x}_{i} \cdot \mathbf{x}_{j}+r\right)$ \\
\hline
\end{tabular}




\section{CHAPTER 4}

\section{RESULTS AND DISCUSSION}

In this study a discriminative classification system is applied to the first-, second- and thirdlevel Enzyme Commission classes defined by IUBMB. The hierarchical tree structure is used to extract representative enzymes for positive and negative training datasets.

Five-fold cross validation is used to evaluate the performance of the system. In five-fold cross validation, the dataset is divided into five folds, four folds are used to train the classifier and one fold is used to test the classifier. The classification is repeated five times so that each fold is used for testing once. In this study, instead of dividing the dataset into five folds randomly, we added representative samples from all sub-sub-subclasses in the EC tree to each fold.

Sensitivity, specificity and area under the ROC (receiver operating characteristic) curve values are used to evaluate the statistical significance of the classification system.

In the binary classification case, the classifier maps the samples to either positive or negative class. The correct and incorrect test results of a classifier can be displayed in a two-by-two confusion matrix as shown in Table 4.1.

Table 4.1: Confusion Matrix

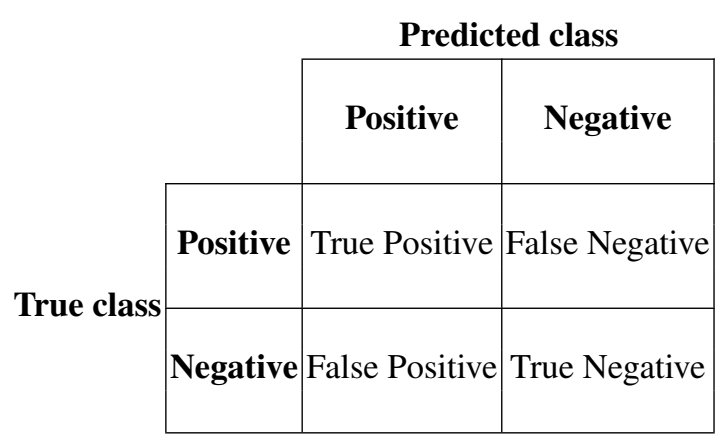


Sensitivity (Equation 4.1) is the probability of correctly classified positive enzymes among all positive enzymes in the test dataset.

$$
\text { sensitivity }=\frac{\text { True positives }}{\text { True positives }+ \text { False negatives }}
$$

Specificity (Equation 4.2) is the probability of correctly classified negative enzymes among all negative enzymes in the test dataset.

$$
\text { specificity }=\frac{\text { True negatives }}{\text { True negatives }+ \text { False positives }}
$$

Area under the ROC (receiver operating characteristic) curve represents the probability that the classifier will rank a randomly chosen positive sample higher than a randomly chosen negative sample [9].

\subsection{First-Level EC Classification Results}

Classification is performed among six major EC classes at the first-level. Table 4.2 shows average five-fold cross validation results for classification of oxidoreductases (EC 1), transferases (EC 2), hydrolases (EC 3), lyases (EC 4), isomerases (EC 5) and ligases (EC 6), respectively. The results are promising to continue the classification task at the second-level.

The average sensitivity values for oxidoreductases (EC 1), transferases (EC 2), hydrolases (EC 3), lyases (EC 4), isomerases (EC 5) and ligases (EC 6) are 92.08\%, 93.38\%, 92.84\%, $91.24 \%, 91.76 \%$ and $97.16 \%$, respectively.

The average specificity values for oxidoreductases (EC 1), transferases (EC 2), hydrolases (EC 3), lyases (EC 4), isomerases (EC 5) and ligases (EC 6) are 99.20\%, 96.86\%, 97.92\%, $99.90 \%, 99.94 \%$ and $99.90 \%$, respectively.

The average AUC values for oxidoreductases (EC 1), transferases (EC 2), hydrolases (EC 3), lyases (EC 4), isomerases (EC 5) and ligases (EC 6) are 0.992, 0.989, 0.991, 0.992, 0.994 and 0.998 , respectively.

We didn't decompose the results for all five folds, but the results are very close to each other 
for all five folds, demonstrating the positive and negative datasets represent the classes well.

Table 4.2: Average Five-fold Cross Validation Results for the FirstLevel EC Classes, TP : True Positives, FP : False Positives, TN

: True Negatives, FN : False Negatives, sens. : sensitivity, spec.

: specificity, AUC : Area under the ROC curve.

\begin{tabular}{|c|c|c|c|c|c|c|c|}
\hline EC Class & $\mathbf{T P}$ & $\mathbf{F P}$ & $\mathbf{T N}$ & FN & $\begin{array}{l}\text { sens. } \\
(\%)\end{array}$ & $\begin{array}{l}\text { spec. } \\
(\%)\end{array}$ & AUC \\
\hline EC 1 Oxidoreductases & 18255 & 323 & 39807 & 1567 & 92.08 & 99.20 & 0.992 \\
\hline EC 2 Transferases & 28155 & 993 & 30601 & 1990 & 93.38 & 96.86 & 0.989 \\
\hline EC 3 Hydrolases & 24766 & 780 & 36933 & 1907 & 92.84 & 97.92 & 0.991 \\
\hline EC 4 Lyases & 12229 & 25 & 43421 & 1166 & 91.24 & 99.90 & 0.992 \\
\hline EC 5 Isomerases & 7055 & 6 & 45663 & 631 & 91.76 & 99.94 & 0.994 \\
\hline EC 6 Ligases & 17470 & 40 & 42372 & 511 & 97.16 & 99.90 & 0.998 \\
\hline
\end{tabular}

\subsection{Second-Level EC Classification Results}

In the second level, 57 sub-classes which have more than 25 enzymes are selected for classification among 60 sub-classes. Table 4.3 shows average five-fold cross validation results for second-level EC sub-classes. The average sensitivity values are in the range $83.08 \%$ to $100 \%$ except sub-classes EC 1.12 and EC 3.8. Table 4.4 and Table 4.5 show the five-fold crossvalidation results for EC 1.12 and EC 3.8. The low average sensitivity value, $64.28 \%$ for EC 1.12 is because of the unbalanced distribution of the datasets where there are 56 enzymes in each fold of the positive dataset and about 16918 enzymes in each fold of the negative dataset for this sub-class. Sub-class EC 3.8 has $76.66 \%$ average sensitivity because of the same reason. The average specificity values are over $98 \%$ for all sub-classes demonstrating that the negative datasets have enough number of representative enzymes. Although the datasets are different, if we compare the accuracy values, our results are better than the second-level 
classification results presented in Chapter 2, establishing that our training datasets are well identified to discriminate the positive and negative classes.

Table 4.3: Average Five-fold Cross Validation Results for the Second-Level EC Classes, TP : True Positives , FP : False Positives, TN : True Negatives, FN : False Negatives, sens. : sensitivity, spec. : specificity, AUC : Area under the ROC curve.

\begin{tabular}{lrrrrrrr}
\hline & & & & & sens. & spec. & \\
EC C1ass & TP & FP & TN & FN & $(\boldsymbol{\%})$ & $(\boldsymbol{\%})$ & AUC \\
\hline EC 1.1 & 5237 & 17 & 14778 & 235 & 95.70 & 99.88 & 0.997 \\
EC 1.2 & 2143 & 0 & 17995 & 122 & 94.58 & 100 & 0.998 \\
EC 1.3 & 1287 & 1 & 18833 & 136 & 90.42 & 99.98 & 0.995 \\
EC 1.4 & 995 & 0 & 19208 & 65 & 93.84 & 100 & 0.998 \\
EC 1.5 & 844 & 0 & 19323 & 110 & 88.44 & 100 & 0.991 \\
EC 1.6 & 2924 & 5 & 17231 & 89 & 97.04 & 99.92 & 0.998 \\
EC 1.7 & 636 & 0 & 19567 & 43 & 93.68 & 100 & 0.998 \\
EC 1.8 & 833 & 0 & 19389 & 50 & 94.34 & 100 & 0.997 \\
EC 1.9 & 486 & 0 & 19647 & 99 & 83.08 & 100 & 0.995 \\
EC 1.10 & 162 & 0 & 20089 & 8 & 95.30 & 100 & 0.998 \\
EC 1.11 & 692 & 0 & 19496 & 68 & 91.06 & 100 & 0.994 \\
EC 1.12 & 45 & 0 & 20204 & 25 & 64.28 & 100 & 0.990 \\
EC 1.13 & 329 & 0 & 19907 & 36 & 90.08 & 100 & 0.993 \\
EC 1.14 & 880 & 0 & 19276 & 106 & 89.26 & 100 & 0.995 \\
EC 1.15 & 395 & 0 & 19838 & 25 & 94.04 & 100 & 0.996 \\
EC 1.16 & 85 & 0 & 20264 & 10 & 89.48 & 100 & 0.999 \\
EC 1.17 & 749 & 0 & 19457 & 37 & 95.30 & 100 & 0.995 \\
EC 1.18 & 178 & 0 & 20071 & 22 & 89.00 & 100 & 0.996 \\
EC 1.20 & 9 & 0 & 20231 & 1 & 90.00 & 100 & 1.000 \\
EC 1.21 & 19 & 0 & 20242 & 2 & 92.00 & 100 & 1.000 \\
EC 1.97 & 48 & 0 & 20205 & 2 & 96.00 & 100 & 1.000 \\
EC 2.1 & 6015 & 12 & 38812 & 421 & 93.44 & 99.90 & 0.997
\end{tabular}


Table 4.3 - Continued

\begin{tabular}{|c|c|c|c|c|c|c|c|}
\hline EC Class & $\mathbf{T P}$ & $\mathbf{F P}$ & $\mathbf{T N}$ & FN & $\begin{array}{l}\text { sens. } \\
(\%)\end{array}$ & $\begin{array}{l}\text { spec. } \\
(\%)\end{array}$ & AUC \\
\hline EC 2.2 & 996 & 0 & 44275 & 18 & 98.20 & 100 & 0.999 \\
\hline EC 2.3 & 3100 & 5 & 41694 & 397 & 88.66 & 99.96 & 0.994 \\
\hline EC 2.4 & 5093 & 14 & 39775 & 373 & 93.20 & 99.92 & 0.996 \\
\hline EC 2.5 & 3595 & 3 & 41352 & 321 & 91.78 & 99.94 & 0.996 \\
\hline EC 2.6 & 1399 & 0 & 43856 & 57 & 96.08 & 100 & 0.999 \\
\hline EC 2.7 & 21864 & 277 & 22443 & 575 & 97.46 & 98.78 & 0.998 \\
\hline EC 2.8 & 803 & 0 & 44439 & 57 & 93.36 & 100 & 0.998 \\
\hline EC 2.9 & 80 & 0 & 45213 & 0 & 100 & 100 & 1.000 \\
\hline EC 3.1 & 7928 & 155 & 18516 & 694 & 91.98 & 99.16 & 0.994 \\
\hline EC 3.2 & 1960 & 23 & 24951 & 366 & 84.28 & 99.90 & 0.993 \\
\hline EC 3.3 & 231 & 0 & 27041 & 9 & 96.24 & 100 & 0.999 \\
\hline EC 3.4 & 3801 & 12 & 23105 & 363 & 91.28 & 99.90 & 0.994 \\
\hline EC 3.5 & 5044 & 6 & 21870 & 389 & 92.82 & 99.94 & 0.994 \\
\hline EC 3.6 & 6110 & 8 & 20947 & 203 & 96.78 & 99.94 & 0.998 \\
\hline EC 3.7 & 82 & 0 & 27218 & 3 & 96.46 & 100 & 1.000 \\
\hline EC 3.8 & 23 & 0 & 27292 & 7 & 76.66 & 100 & 1.000 \\
\hline EC 3.11 & 38 & 0 & 27252 & 2 & 95.00 & 100 & 1.000 \\
\hline EC 4.1 & 4719 & 20 & 8893 & 153 & 96.86 & 99.76 & 0.999 \\
\hline EC 4.2 & 6568 & 13 & 7077 & 134 & 98.00 & 99.84 & 0.999 \\
\hline EC 4.3 & 867 & 0 & 12872 & 41 & 95.50 & 100 & 0.996 \\
\hline EC 4.4 & 334 & 0 & 13434 & 15 & 95.70 & 100 & 0.999 \\
\hline EC 4.6 & 408 & 0 & 13277 & 12 & 97.66 & 100 & 0.999 \\
\hline EC 4.99 & 432 & 0 & 13338 & 13 & 97.10 & 100 & 0.998 \\
\hline EC 5.1 & 1211 & 1 & 6533 & 32 & 97.42 & 99.98 & 0.998 \\
\hline EC 5.2 & 638 & 0 & 5822 & 47 & 93.12 & 100 & 0.999 \\
\hline EC 5.3 & 3051 & 9 & 4656 & 58 & 98.14 & 99.82 & 0.999 \\
\hline EC 5.4 & 2212 & 0 & 5517 & 62 & 97.28 & 100 & 0.998 \\
\hline EC 5.5 & 80 & 0 & 7705 & 5 & 94.10 & 100 & 0990 \\
\hline EC 5.99 & 361 & 1 & 7406 & 24 & 93.76 & 99.98 & 0.999 \\
\hline
\end{tabular}


Table 4.3 - Continued

\begin{tabular}{lrrrrrrr}
\hline EC Class & TP & FP & TN & FN & $(\%)$ & $(\%)$ & AUC \\
\hline EC 6.1 & 9479 & 11 & 7569 & 18 & 99.76 & 99.82 & 0.999 \\
EC 6.2 & 746 & 0 & 17264 & 14 & 98.12 & 100 & 0.999 \\
EC 6.3 & 6359 & 11 & 11590 & 56 & 99.08 & 99.90 & 0.999 \\
EC 6.4 & 610 & 0 & 17398 & 7 & 98.84 & 100 & 0.999 \\
EC 6.5 & 724 & 0 & 17276 & 16 & 97.76 & 100 & 0.998 \\
EC 6.6 & 30 & 0 & 17985 & 5 & 85.70 & 100 & 0.993 \\
\hline
\end{tabular}


Table 4.4: Five-fold Cross Validation Results for EC 1.12, TP :

True Positives, FN : False Negatives, TN : True Negatives, FP

: False Positives, sens. : sensitivity, spec. : specificity, AUC :

Area under the ROC curve.

\section{EC 1.12}

\begin{tabular}{lccccccccc}
\hline & Positive & Negative & \multicolumn{2}{c}{ Positive Test } & \multicolumn{2}{c}{ Negative Test } & & & \\
& Training & Training & tp & fn & tn & fp & sens. & spec. & AUC \\
Fold 1 & 56 & 16921 & 9 & 5 & 4034 & 0 & 0.643 & 1.0 & 0.972 \\
Fold 2 & 56 & 16921 & 9 & 5 & 4063 & 0 & 0.643 & 1.0 & 1.0 \\
Fold 3 & 56 & 16914 & 10 & 4 & 4041 & 0 & 0.714 & 1.0 & 0.999 \\
Fold 4 & 56 & 16922 & 6 & 8 & 4027 & 0 & 0.429 & 1.0 & 0.986 \\
Fold 5 & 56 & 16916 & 11 & 3 & 4039 & 0 & 0.785 & 1.0 & 0.995 \\
\hline
\end{tabular}

Table 4.5: Five-fold Cross Validation Results for EC 3.8, TP :

True Positives, FN : False Negatives, TN : True Negatives, FP

: False Positives, sens. : sensitivity, spec. : specificity, AUC :

Area under the ROC curve.

\section{EC 3.8}

\begin{tabular}{lccccccccc}
\hline & Positive & Negative & \multicolumn{2}{c}{ Positive Test } & \multicolumn{2}{c}{ Negative Test } & sens. & spec. & AUC \\
& Training & Training & tp & fn & tn & $\mathbf{f p}$ & $(\boldsymbol{\%})$ & $(\boldsymbol{\%})$ & $(\boldsymbol{\%})$ \\
Fold 1 & 28 & 22614 & 6 & 0 & 5449 & 0 & 100 & 100 & 100 \\
Fold 2 & 28 & 22616 & 5 & 1 & 5470 & 0 & 83,3 & 100 & 100 \\
Fold 3 & 28 & 22615 & 4 & 2 & 5468 & 0 & 66,7 & 100 & 100 \\
Fold 4 & 28 & 22611 & 5 & 1 & 5449 & 0 & 83,3 & 100 & 100 \\
Fold 5 & 28 & 22626 & 3 & 3 & 5456 & 0 & 50 & 100 & 100 \\
\hline
\end{tabular}




\subsection{Third-Level EC Classification Results}

The classification is performed by 140 sub-subclasses shown in Table 4.6, which have more than 25 enzymes at the third-level. The sub-classes of EC 1.9, EC 1.11, EC 1.15, EC 1.97, EC 2.2, EC 2.5, EC 2.9, EC 3.7, EC 3.8, EC 3.11, EC 4.4, EC 4.6, EC 4.99, EC 5.2, EC 5.5, EC 5.99, EC 6.1, EC 6.2, EC 6.4, EC 6.5 and EC 6.6 have only one sub-subclass at the third level, therefore the classification at the second-level would be sufficient to assign a novel enzyme to these sub-subclasses. The predictive results for the third-level classifications are good for most of the sub-subclasses. Among 140 sub-subclasses, the average sensitivity values of 11 sub-subclasses are less than $80.00 \%$. These sub-subclasses are EC 1.1.3, EC 1.2.7, EC 1.2.99, 1.3.99, EC 1.5.3, EC 1.7.3, EC 1.8.3, EC 1.16.1, EC 1.18.1, EC 3.1.21, EC 3.4.16. There are very small number of enzymes in the positive training datasets of these sub-subclasses. When the sensitivity values of each fold of the sub-subclasses having small number of positive samples are observed, it is seen that sensitivity values are very high for some folds and very low for some other folds. But when we look at the classes with sufficient number of training samples, the results for all folds are consistent and high. The average specificity values for all sub-subclasses are over 95.00\% except EC 1.5.1 and EC 1.13.11, since there are sufficient number of negative training samples for most of the sub-subclasses. The number of negative samples in the datasets of EC 1.5.1 and EC 1.13.11 are few and less than the number of positive samples, therefore average specificity values of these subsubclasses are less than the remaining sub-subclasses. Average AUC values are over 0.95 for all of the sub-subclasses.

Table 4.6: Average Five-fold Cross Validation Results for the Third-Level EC Classes, TP : True Positives, FP : False Positives , TN : True Negatives, FN : False Negatives, sens. : sensitivity, spec. : specificity, AUC : Area under the ROC curve.

\begin{tabular}{lrrrrccr}
\hline EC Class & TP & FP & TN & FN & $(\%)$ & $(\%)$ & AUC \\
\hline EC 1.1.1 & 5295 & 24 & 454 & 0 & 100 & 95.10 & 0.998 \\
EC 1.1.2 & 59 & 0 & 5707 & 6 & 90.96 & 100 & 1.000
\end{tabular}


Table 4.6 - Continued

\begin{tabular}{lrrrrrrr}
\hline & & & & & sens. & spec. & \\
EC C1ass & TP & FP & TN & FN & $(\boldsymbol{\%})$ & $(\boldsymbol{\%})$ & AUC \\
\hline EC 1.1.3 & 38 & 0 & 5724 & 16 & 77.62 & 100 & 0.996 \\
EC 1.1.99 & 328 & 0 & 5423 & 23 & 93.72 & 100 & 0.996 \\
EC 1.2.1 & 2016 & 2 & 340 & 14 & 99.30 & 99.48 & 0.999 \\
EC 1.2.4 & 193 & 0 & 2167 & 12 & 94.18 & 100 & 0.998 \\
EC 1.2.7 & 35 & 0 & 2309 & 30 & 54.12 & 100 & 0.999 \\
EC 1.2.99 & 25 & 0 & 2326 & 24 & 51.84 & 100 & 0.994 \\
EC 1.3.1 & 698 & 0 & 839 & 30 & 96.04 & 100 & 0.998 \\
EC 1.3.3 & 592 & 0 & 958 & 16 & 97.28 & 100 & 0.999 \\
EC 1.3.5 & 41 & 0 & 1521 & 5 & 89.12 & 100 & 1.000 \\
EC 1.3.7 & 46 & 0 & 1515 & 4 & 92.88 & 100 & 0.999 \\
EC 1.3.99 & 103 & 0 & 1431 & 32 & 77.42 & 100 & 0.986 \\
EC 1.4.1 & 166 & 0 & 938 & 17 & 91.16 & 100 & 0.999 \\
EC 1.4.3 & 410 & 2 & 695 & 14 & 96.70 & 99.70 & 0.999 \\
EC 1.4.4 & 382 & 0 & 739 & 0 & 100 & 100 & 1.000 \\
EC 1.4.99 & 114 & 0 & 1000 & 7 & 94.30 & 100 & 0.999 \\
EC 1.5.1 & 929 & 9 & 81 & 4 & 99.60 & 89.66 & 0.991 \\
EC 1.5.3 & 9 & 0 & 998 & 16 & 34.66 & 100 & 0.973 \\
EC 1.5.99 & 41 & 0 & 970 & 9 & 83.00 & 100 & 0.998 \\
EC 1.6.1 & 76 & 0 & 2953 & 4 & 94.82 & 100 & 1.000 \\
EC 1.6.2 & 106 & 0 & 2929 & 1 & 99.04 & 100 & 1.000 \\
EC 1.6.5 & 1240 & 26 & 1705 & 41 & 96.80 & 98.50 & 0.997 \\
EC 1.6.99 & 1490 & 6 & 1471 & 45 & 97.08 & 99.62 & 0.998 \\
EC 1.7.1 & 466 & 1 & 239 & 7 & 98.54 & 99.54 & 0.999 \\
EC 1.7.2 & 72 & 0 & 639 & 0 & 100 & 100 & 1.000 \\
EC 1.7.3 & 20 & 0 & 682 & 9 & 67.62 & 100 & 0.972 \\
EC 1.7.99 & 121 & 0 & 582 & 8 & 93.66 & 100 & 0.999 \\
EC 1.1 & 397 & 0 & 518 & 3 & 99.26 & 100 & 0.999 \\
EC 1.3 & 28 & 0 & 879 & 10 & 73.42 & 100 & 0.998 \\
\hline & & & 485 & 2 & 99.54 & 100 & 1.000
\end{tabular}


Table 4.6 - Continued

\begin{tabular}{|c|c|c|c|c|c|c|c|}
\hline EC Class & $\mathbf{T P}$ & $\mathbf{F P}$ & TN & FN & $\begin{array}{l}\text { sens. } \\
(\%)\end{array}$ & $\begin{array}{l}\text { spec. } \\
(\%)\end{array}$ & AUC \\
\hline EC 1.8.98 & 28 & 0 & 884 & 5 & 85.22 & 100 & 1.000 \\
\hline EC 1.10.2 & 37 & 0 & 151 & 2 & 94.64 & 100 & 0.999 \\
\hline EC 1.10 .3 & 91 & 0 & 97 & 2 & 97.88 & 100 & 1.000 \\
\hline EC 1.10.99 & 58 & 0 & 132 & 0 & 100 & 100 & 1.000 \\
\hline EC 1.12.99 & 31 & 0 & 48 & 4 & 88.56 & 100 & 0.984 \\
\hline EC 1.13.11 & 394 & 6 & 27 & 0 & 100 & 85.50 & 0.998 \\
\hline EC 1.14.11 & 101 & 0 & 1046 & 23 & 81.72 & 100 & 0.998 \\
\hline EC 1.14.12 & 74 & 0 & 1092 & 9 & 90.54 & 100 & 0.990 \\
\hline EC 1.14.13 & 217 & 0 & 897 & 61 & 80.48 & 100 & 0.982 \\
\hline EC 1.14.14 & 296 & 8 & 854 & 20 & 93.66 & 99.04 & 0.998 \\
\hline EC 1.14.15 & 35 & 4 & 1125 & 7 & 86.88 & 99.62 & 0.977 \\
\hline EC 1.14.16 & 31 & 0 & 1145 & 3 & 90.00 & 100 & 1.000 \\
\hline EC 1.14.17 & 35 & 0 & 1138 & 4 & 89.16 & 100 & 1.000 \\
\hline EC 1.14.18 & 33 & 0 & 1137 & 8 & 80.56 & 100 & 0.999 \\
\hline EC 1.14.19 & 31 & 0 & 1146 & 3 & 91.10 & 100 & 0.997 \\
\hline EC 1.14.99 & 166 & 0 & 997 & 9 & 95.18 & 100 & 0.993 \\
\hline EC 1.16.1 & 17 & 0 & 84 & 9 & 67.68 & 100 & 0.997 \\
\hline EC 1.16.3 & 78 & 0 & 27 & 5 & 93.90 & 100 & 0.992 \\
\hline EC 1.17.1 & 312 & 0 & 479 & 10 & 96.94 & 100 & 0.999 \\
\hline EC 1.17.4 & 471 & 2 & 327 & 1 & 99.78 & 99.42 & 1.000 \\
\hline EC 1.18.1 & 53 & 0 & 141 & 14 & 79.56 & 100 & 0.999 \\
\hline EC 1.18.6 & 138 & 1 & 66 & 3 & 97.84 & 98.46 & 0.996 \\
\hline EC 2.1.1 & 3832 & 16 & 2879 & 8 & 99.78 & 99.44 & 0.999 \\
\hline EC 2.1.2 & 2006 & 0 & 4721 & 8 & 99.62 & 100 & 0.999 \\
\hline EC 2.1.3 & 863 & 0 & 5865 & 7 & 99.20 & 100 & 0.998 \\
\hline EC 2.3.1 & 3343 & 27 & 797 & 6 & 99.82 & 96.74 & 0.998 \\
\hline EC 2.3.2 & 418 & 0 & 3742 & 19 & 95.70 & 100 & 0.999 \\
\hline EC 2.3.3 & 375 & 3 & 3782 & 12 & 96.94 & 99.94 & 0.999 \\
\hline EC 2.4.1 & 2274 & 20 & 3380 & 21 & 99.12 & 99.42 & 0.999 \\
\hline
\end{tabular}


Table 4.6 - Continued

\begin{tabular}{lrrrrrrr}
\hline & & & & & sens. & spec. & \\
EC Class & TP & FP & TN & FN & $(\boldsymbol{\%})$ & $(\boldsymbol{\%})$ & AUC \\
\hline EC 2.4.2 & 3320 & 4 & 2327 & 43 & 98.74 & 99.84 & 0.999 \\
EC 2.4.99 & 38 & 0 & 5659 & 0 & 100 & 100 & 1.000 \\
EC 2.6.1 & 1293 & 0 & 198 & 0 & 100 & 100 & 1.000 \\
EC 2.6.99 & 189 & 0 & 1299 & 0 & 100 & 100 & 1.000 \\
EC 2.7.1 & 4795 & 19 & 18265 & 255 & 94.26 & 99.90 & 0.997 \\
EC 2.7.2 & 1647 & 0 & 21725 & 23 & 98.62 & 100 & 0.999 \\
EC 2.7.3 & 99 & 0 & 19284 & 9 & 91.74 & 100 & 0.999 \\
EC 2.7.4 & 2908 & 2 & 20420 & 64 & 97.84 & 99.96 & 0.998 \\
EC 2.7.6 & 252 & 2 & 23130 & 11 & 95.90 & 99.98 & 0.995 \\
EC 2.7.7 & 8327 & 83 & 14743 & 214 & 97.52 & 99.44 & 0.999 \\
EC 2.7.8 & 1049 & 2 & 22291 & 40 & 96.34 & 99.98 & 0.996 \\
EC 2.7.9 & 119 & 0 & 23255 & 6 & 95.36 & 100 & 1.000 \\
EC 2.7.10 & 440 & 0 & 22904 & 32 & 93.22 & 100 & 0.998 \\
EC 2.7.11 & 2378 & 39 & 20873 & 105 & 95.80 & 99.82 & 0.999 \\
EC 2.7.12 & 87 & 0 & 23280 & 19 & 82.04 & 100 & 0.999 \\
EC 2.7.13 & 412 & 0 & 22935 & 27 & 93.84 & 100 & 0.999 \\
EC 2.8.1 & 808 & 0 & 204 & 9 & 98.74 & 100 & 0.999 \\
EC 2.8.2 & 98 & 0 & 828 & 4 & 96.80 & 100 & 0.999 \\
EC 2.8.3 & 61 & 0 & 864 & 5 & 92.90 & 100 & 0.999 \\
EC 2.8.4 & 30 & 0 & 894 & 6 & 83.92 & 100 & 0.999 \\
EC 3.1.1 & 1696 & 15 & 7172 & 113 & 93.80 & 99.78 & 0.997 \\
EC 3.1.2 & 450 & 0 & 8514 & 36 & 92.60 & 100 & 0.992 \\
EC 3.1.3 & 1830 & 7 & 6987 & 191 & 90.56 & 99.90 & 0.996 \\
EC 3.1.4 & 506 & 0 & 8407 & 92 & 84.58 & 100 & 0.995 \\
EC 3.1.5 & 30 & 0 & 8975 & 1 & 96.66 & 100 & 1.000 \\
EC 3.1.6 & 27 & 0 & 8973 & 6 & 80.84 & 100 & 0.968 \\
EC 3.11 & 602 & 0 & 8360 & 36 & 94.40 & 100 & 0.997 \\
\hline & 104 & 0 & 8889 & 16 & 86.92 & 100 & 0.997 \\
\hline & 0 & 8614 & 118 & 69.68 & 100 & 0.972
\end{tabular}


Table 4.6 - Continued

\begin{tabular}{|c|c|c|c|c|c|c|c|}
\hline EC Class & $\mathbf{T P}$ & $\mathbf{F P}$ & $\mathbf{T N}$ & FN & $\begin{array}{l}\text { sens. } \\
(\%)\end{array}$ & $\begin{array}{r}\text { spec. } \\
(\%)\end{array}$ & $\mathbf{A U C}$ \\
\hline EC 3.1.22 & 408 & 0 & 8598 & 7 & 98.32 & 100 & 0.998 \\
\hline EC 3.1.26 & 2139 & 0 & 6768 & 87 & 96.08 & 100 & 0.998 \\
\hline EC 3.1.27 & 192 & 0 & 8793 & 21 & 90.30 & 100 & 0.999 \\
\hline EC 3.2.1 & 1882 & 25 & 582 & 7 & 99.62 & 95.94 & 0.999 \\
\hline EC 3.2.2 & 561 & 0 & 1890 & 46 & 92.46 & 100 & 0.997 \\
\hline EC 3.3.1 & 192 & 0 & 62 & 1 & 99.50 & 100 & 0.999 \\
\hline EC 3.3.2 & 58 & 0 & 193 & 4 & 93.76 & 100 & 0.999 \\
\hline EC 3.4.11 & 574 & 0 & 4229 & 43 & 93.08 & 100 & 0.995 \\
\hline EC 3.4.13 & 131 & 0 & 4696 & 14 & 90.36 & 100 & 0.994 \\
\hline EC 3.4.14 & 79 & 0 & 4754 & 9 & 89.50 & 100 & 0.999 \\
\hline EC 3.4.16 & 25 & 0 & 4796 & 19 & 56.00 & 100 & 0.968 \\
\hline EC 3.4.17 & 59 & 0 & 4770 & 10 & 87.32 & 100 & 0.980 \\
\hline EC 3.4.19 & 141 & 0 & 4688 & 23 & 86.08 & 100 & 0.993 \\
\hline EC 3.4.21 & 1614 & 3 & 3165 & 60 & 96.58 & 99.90 & 0.998 \\
\hline EC 3.4.22 & 280 & 0 & 4526 & 35 & 90.14 & 100 & 0.998 \\
\hline EC 3.4.23 & 482 & 0 & 4342 & 19 & 96.42 & 100 & 0.999 \\
\hline EC 3.4.24 & 894 & 0 & 3924 & 24 & 97.52 & 100 & 0.999 \\
\hline EC 3.4.25 & 272 & 0 & 4561 & 10 & 96.44 & 100 & 0.999 \\
\hline EC 3.5.1 & 1724 & 11 & 3877 & 100 & 94.62 & 99.72 & 0.998 \\
\hline EC 3.5.2 & 609 & 0 & 5074 & 31 & 95.16 & 100 & 0.996 \\
\hline EC 3.5.3 & 505 & 0 & 5197 & 11 & 97.92 & 100 & 0.999 \\
\hline EC 3.5.4 & 2416 & 0 & 3244 & 52 & 97.92 & 100 & 0.999 \\
\hline EC 3.5.99 & 244 & 0 & 5461 & 8 & 96.92 & 100 & 0.997 \\
\hline EC 3.6.1 & 2562 & 6 & 4096 & 15 & 99.40 & 99.86 & 0.999 \\
\hline EC 3.6.3 & 4041 & 4 & 2624 & 14 & 99.64 & 99.84 & 0.999 \\
\hline EC 3.6.4 & 25 & 0 & 6655 & 2 & 92.00 & 100 & 1.000 \\
\hline EC 4.1.1 & 3767 & 31 & 1201 & 22 & 99.44 & 97.54 & 0.999 \\
\hline EC 4.1.2 & 569 & 0 & 4412 & 44 & 92.90 & 100 & 0.997 \\
\hline EC 4.1.3 & 362 & 0 & 4629 & 26 & 93.34 & 100 & 0.996 \\
\hline
\end{tabular}


Table 4.6 - Continued

sens. spec.

\begin{tabular}{lrrrrrrr} 
EC Class & TP & FP & TN & FN & $(\boldsymbol{\%})$ & $(\boldsymbol{\%})$ & \multicolumn{1}{l}{ AUC } \\
\hline EC 4.1.99 & 219 & 0 & 4792 & 10 & 95.60 & 100 & 0.999 \\
EC 4.2.1 & 5329 & 30 & 1494 & 11 & 99.78 & 98.06 & 0.999 \\
EC 4.2.2 & 78 & 0 & 6765 & 21 & 81.76 & 100 & 0.999 \\
EC 4.2.3 & 917 & 0 & 5917 & 31 & 96.76 & 100 & 0.999 \\
EC 4.2.99 & 461 & 0 & 6388 & 16 & 96.66 & 100 & 0.999 \\
EC 4.3.1 & 418 & 2 & 512 & 8 & 98.18 & 99.60 & 0.999 \\
EC 4.3.2 & 504 & 0 & 431 & 5 & 99.00 & 100 & 1.000 \\
EC 5.1.1 & 794 & 0 & 567 & 8 & 99.02 & 100 & 0.999 \\
EC 5.1.2 & 137 & 0 & 1233 & 1 & 99.32 & 100 & 0.998 \\
EC 5.1.3 & 409 & 1 & 946 & 14 & 96.86 & 99.90 & 0.999 \\
EC 5.3.1 & 2768 & 4 & 484 & 8 & 99.72 & 99.16 & 0.999 \\
EC 5.3.3 & 340 & 0 & 2903 & 19 & 94.74 & 100 & 0.998 \\
EC 5.3.4 & 63 & 0 & 3195 & 4 & 93.84 & 100 & 1.000 \\
EC 5.3.99 & 46 & 0 & 3213 & 4 & 92.24 & 100 & 1.000 \\
EC 5.4.2 & 1393 & 0 & 912 & 13 & 99.06 & 100 & 0.999 \\
EC 5.4.3 & 368 & 0 & 1946 & 3 & 99.20 & 100 & 0.999 \\
EC 5.4.99 & 502 & 0 & 1796 & 19 & 96.34 & 100 & 0.999 \\
EC 6.3.1 & 437 & 0 & 6043 & 19 & 95.90 & 100 & 0.999 \\
EC 6.3.2 & 2656 & 1 & 3833 & 15 & 99.42 & 99.98 & 0.999 \\
EC 6.3.3 & 510 & 0 & 5980 & 10 & 98.08 & 100 & 0.998 \\
EC 6.3.4 & 1704 & 0 & 4779 & 16 & 99.06 & 100 & 0.999 \\
EC 6.3.5 & 1118 & 0 & 5366 & 14 & 98.76 & 100 & 0.999 \\
\hline & & & & & & & \\
\hline
\end{tabular}




\subsection{Discussion}

In this thesis, we used a top-down approach for prediction of Enzyme Commission classes. Since we performed five-fold cross-validation, we prepared 1015 positive and 1015 negative datasets for 203 classes. We developed an algorithm to select representative samples from the hierarchical tree structure for the positive and negative datasets of a class, to improve the performance of the classification model we used. We trained 30, 285, 700 classifiers for the first-, second- and third-level classes, respectively. Average sensitivity, specificity and AUC results are very good for the first-level classes as we expected, because the number of positive and negative samples belonging to the classes at this level are more than enough to make an accurate distinction. The results are also good for the second-level subclasses, except for only two subclasses. At the third-level the prediction results are better than expected, since the number of positive samples belonging to sub-subclasses at this level are very few compared to the higher levels. 


\section{CHAPTER 5}

\section{CONCLUSION AND FUTURE WORK}

In this thesis, we developed a three-level classification system for the prediction of enzyme classes. Our emphasis in this thesis was on the selection of positive and negative enzymes for training datasets to improve the predictive performance of the discriminative model. We developed an algorithm to prepare positive and negative datasets for the classes represented in the four-level hierarchical tree structure by IUBMB. We used a subsequence-based approach, Subsequence Profile Map (SPMap), to generate features from primary sequences of enzymes. The results were satisfactory for the first- and second-level classes, as well as most of the classes at the third-level.

For future work, classification between enzymes and non-enzymes can be performed by using the same algorithm developed in this study to extract the enzymes from the hierarchical tree structure and developing an algorithm to select representative non-enzyme proteins.

In this study, negative enzymes are selected from the classes having the same parent as the positive class, at the higher level. For two EC numbers EC $x_{1} \cdot x_{2} \cdot x_{3} \cdot x_{4}$ and EC $y_{1} \cdot y_{2} \cdot y_{3} \cdot y_{4}$, if $x_{1}=y 1$ and $x_{2} \neq y_{2}$, the enzymes belonging to these numbers catalyze the same reactions at the first-level, but the type of the substrate is different at the second-level. For our case, to give an example, for the EC class, EC 1.1, negative examples are selected from the remaining subclasses EC 1.x, $x=2, \ldots, 97$. For further consideration, since same digits representing the level in the EC number, refers to the same function, negative enzymes can be selected from the classes with different parents at the higher level, but with same function at the same level. For the same EC class, EC 1.1, the negative enzymes can be selected from EC $y .1, y=2, \ldots 6$. Thus, negative samples may be far away from the positive samples in the feature space.

SPMap was used to classify the enzyme datasets prepared by Lu et al. [29] and the results 
were presented in [35]. These datasets were constructed by removing proteins having more than $25 \%$ sequence identity. Since we claim that our datasets are more discriminative, SPMap method can be compared by other feature extraction methods using the datasets we prepared in this study. Amino acid composition of enzymes can be used to generate feature vectors and SVMs can be used for classification. The results can be compared with the results obtained in this study. 


\section{REFERENCES}

[1] Altschul,S., Gish,W., Miller,W., Myers,E.W., and Lipman,D. J. (1990) Basic local alignment search tool. Y. Mol. Biol. 215:403-410.

[2] Apweiler, R., Attwood, T.K., Bairoch, A., Bateman, A., Birney, E., Biswas, M., Bucher, P., Cerutti, L., Corpet, F., Croning, M.D.R., Durbin, R., Falquet, L., Fleischmann, W., Gouzy, L., Hermjakob, H., Hulo, N., Jonasses, I., Kahn, D., Kanapin, A., Karavidopoulou, Y., Lopez, R., Marx, B., Mulder, N.J., Oinn, T.M., Pagni, M., Servant, F., Sigrist, C.J.A., Zdobnov, E.M. (2001) The InterPro database, an integrated documentation resource for protein families, domains and functional sites. Nucleic Acids Res. 29, $37-40$.

[3] Ashburner,M., Ball,C., Blake,J., Bostein,D., Butler,H., Cherry,J., Davis,A., Dolinski,K., Dwight,S., Eppig,J. et al, (2000) Gene Ontology: tool for the unification of biology. Nature Genetics 25, 25-29.

[4] Attwood,T.K., Croning,M.D.R., Flower,D.R., Lewis,A.P., Mabey,J.E., Scordis,P., Selley,J.N. and Wright,W. (2000) PRINTS-S: the database formerly known as PRINTS. Nucleic Acids Res., 28, 225-227.

[5] Bairoch, A. (2000) The ENZYME database in 2000. Nucleic Acids Research 28, 1, 304305.

[6] Bateman,A., Birney,E., Cerruti,L. Durbin,R., Etwiller,L., Eddy,S.R., Griffiths-Jones,S., Howe,K.L., Marshall,M. and Sonnhammer,E.L. (2002) The Pfam protein families database. Nucleic Acids Res. 30, 276-280.

[7] Ben-hur,A. and Brutlag,D. (2003) Remote homology detection: a motif based approach, Bioinformatics 19, pp. 26-33.

[8] Binnewies,T.T., Motro,Y., Hallin,P.F., Lund,O., Dunn,D., et al. (2006) Ten years of bacterial genome sequencing: comparative-genomics-based discoveries. Func. Integr. Genomics, 6:165:185.

[9] Bradley,A.P. (1997) The use of the area under the ROC curve in the evaluation of machine learning algorithms. Pattern Recognition, 30(7):1145-1159.

[10] Burges, C.J.C. (1998) A tutorial on support vector machines for pattern recognition, Data Mining and Knowledge Discovery, 2, 121-167.

[11] Cai,C.Z., Han,L.Y., Ji,Z.L., Chen,X., Chen,Y.Z. (2003) SVM-Prot: Web-Based Support Vector Machine Software for Functional Classification of a Protein from Its Primary Sequence. Nucleic Acids Res., 31: 3692-3697

[12] Cai,C.Z., Han,L.Y., Ji,Z.L. and Chen,Y.Z. (2004) Enzyme family classification by support vector machines. Proteins, 55, 66-76. 
[13] Cai,Y.D., Chou,K.C. (2005) Using Functional Domain Composition To Predict Enzyme Family Classes. J. Proteome Res. 4, pp. 109-111.

[14] Cai,Y.D., Zhou,G.P., and Chou,K.C. (2005) Predicting enzyme family classes by hybridizing gene product composition and pseudo-amino acid composition, J. Theor. Biol. 234, pp. 145-149.

[15] Chou,K.C. and Elrod,D. (1999) Protein subcellular location prediction. Protein Eng., $12,107-118$.

[16] Chou, K.C. (2001) Prediction of protein cellular attributes using pseudo-amino acid composition. Proteins Struct. Funct. Gen. (Erratum: ibid., 2001. Vol. 44,60) 43, 246255 .

[17] Chou,K.C. and Elrod,D.W. (2003) Prediction of enzyme family classes, J. Proteome Res. 2 , pp. 183-190.

[18] Chou, K.C., Cai, Y.D. (2003) A new hybrid approach to predict subcellular localization of proteins by incorporating Gene ontology. Biochem. Biophys. Res. Commun. 311, 743747.

[19] Chou, K.C. (2005) Using amphiphilic pseudo amino acid composition to predict enzyme subfamily classes. Bioinformatics $21,10-19$.

[20] Corpet,F., Servant,F., Gouzy,J. and Kahn,D. (2000) ProDom and ProDom-CG: tools for protein domain analysis and whole genome comparisons. Nucleic Acids Res., 28, 267269.

[21] Denoeux, T. (1995) A k-nearest neighbor classification rule based on Dempster-Shafer theory. IEEE Trans. Syst. Man. Cybernet. 25, 804-813.

[22] Duda,R.O., Hart,P.E., and Stork,D.G., (2000) Pattern Classification (2nd ed.), WileyInterscience.

[23] Enzyme Nomenclature. Recommendations of the Nomenclature Committee of the International Union of Biochemistry and Molecular Biology on the Nomenclature and Classification of Enyzmes. NC-IUBMB. (Academic, New York, 1992).

[24] Fraser,C.M., Eisen,J.A., Nelson,K.E., Paulsen,I.T. and Salzberg,S.L. (2002) The value of complete microbial genome sequencing (you get what you pay for) Journal of Bacteriology, 184, 6403-6405.

[25] Henikoff S. and Henikoff J. G. (1992). Amino acid substitution matrices from protein blocks. Proc. Natl. Acad. Sci. USA 89, 10915-10919.

[26] Henikoff,J.G., Greene,E.A., Pietrokovski,S. and Henikoff,S. (2000) Increased coverage of protein families with the Blocks Database servers. Nucleic Acids Res., 28, 228-230.

[27] Hulo,N., Bairoch,A., Bulliard,V., Cerutti,L., Castro,E.D., Langendijk-Genevaux,P.S., Pagni,M. and Sigrist,C.J.A. (2006) The PROSITE database. Nucleic Acids Research 34, Database issue, D227-D230.

[28] Joachims, T., (1999) Making large-Scale SVM Learning Practical (Book Chapter). Advances in Kernel Methods-Support Vector Learning MIT Press. 
[29] Lu,L., Qian,Z., Cai,Y. and Li,Y. (2007) ECS: an automatic enzyme classifier based on functional domain composition, Comput. Biol. Chem. 31, pp. 226-232.

[30] Medigue,C. and Moszer,I. (2007) Annotation, comparison and databases for hundreds of bacterial genomes. Res. Microbiol., 158, 724-736.

[31] Pandey, G., Kumar, V., Steinbach, M., (2006) Computational Approaches for Protein Function Prediction. TR 06-028, Department of Computer Science and Engineering, University of Minnesota, Twin Cities.

[32] Pearson, W. (1990) Rapid and sensitive sequence comparison with FASTAP and FASTA. Methods in Enzymology 183:63-98.

[33] Petsko,G.A. and Ringe,D. (2003) Protein Structure and Function, Sinauer Associates, Inc.

[34] Pratt,C.W. and Cornely,K. (2003) Essential Biochemistry, John Wiley High Education.

[35] Sarac,O.S., Yuzugullu,O.G., Cetin-Atalay,R., and Atalay,V. (2008) Subsequence-based feature map for protein function classification, Computational Biology and Chemistry, $32,122-130$.

[36] Scholkopf,B., Burges,C. and Vapnik,V. (1995) Extracting support data for a given task. In Fayyad,U.M. and Uthurusamy,R. (eds), Proceedings of the First International Conference on Knowledge Discovery and Data Mining. AAAI Press, Menlo Park, CA, pp. 252-257.

[37] Schomburg,I., Chang,A., and Schomburg,D. (2002) BRENDA, enzyme data and metabolic information, Nucleic Acids Research 30(1), 47-49.

[38] Shafer, G. (1976) A Mathematical Theory of Evidence Princeton University Press: Princeton, New Jersey.

[39] Shah, I. and Hunter, L. (1997). Predicting enzyme function from sequece: a systematic appraisal. In the proceedings of ISMB 1997 276-283.

[40] Shen,H.B. and Chou,K.C. (2007) EzyPred: A top-down approach for predicting enzyme functional classes and sub-classes. Biochemical and Biophysical Research Communications 364: 53-59.

[41] Stothard,P., Wishart,D.S. (2006) Automated bacterial genome analysis and annotation. Current Opinion in Microbiology 9, pp. 505-510.

[42] Vapnik,V. (1995) The Nature of Statistical Learning Theory. Springer, New York.

[43] Vapnik,V. (1998) Statistical Learning Theory. Wiley, New York.

[44] Wu C.H. Barker W.C. Boeckmann B. Ferro S. Gasteiger E. Huang H. Lopez R. Magrane M. Martin M.J. Natale D.A. O’Donovan C. Redaschi N. Apweiler R., Bairoch A. and Yeh L.S. Uniprot: the universal protein knowledgebase. Nucleic Acids Research, 32:115-119, 2004.

[45] Zouhal,L.M., Denoeux,T. (1998) An evidence-theoretic K-NN rule with parameter optimization. IEEE Trans. Syst. Man. Cybernet. 28, 263-271. 